Article

\title{
A Highly Efficient Ag Nanoparticle-Immobilized Alginate-g-Polyacrylonitrile Hybrid Photocatalyst for the Degradation of Nitrophenols
}

\author{
Imran Hasan ${ }^{1}$, Charu Shekhar ${ }^{1}$, Walaa Alharbi ${ }^{2}$, Maymonah Abu Khanjer ${ }^{3}$, \\ Rais Ahmad Khan ${ }^{3}$ (D) and Ali Alsalme ${ }^{3, *(D)}$ \\ 1 Environmental Research Laboratory, Department of Chemistry, Chandigarh University, Gharuan, \\ Mohali 140301, Punjab, India; imranhasan98@gmail.com (I.H.); charushekhar1998@gmail.com (C.S.) \\ 2 Department of Chemistry, Faculty of Science, King Khalid University, P.O. Box-9004, \\ Abha 62529, Saudi Arabia; Wal-harbe@kku.edu.sa \\ 3 Department of Chemistry, College of Science, King Saud University, Riyadh 11451, Saudi Arabia; \\ moon-700p@hotmail.com (M.A.K.); krais@ksu.edu.sa (R.A.K.) \\ * Correspondence: aalsalme@ksu.edu.sa
}

Received: 18 November 2020; Accepted: 15 December 2020; Published: 19 December 2020

\begin{abstract}
Herein, we report PAN-g-Alg@Ag-based nanocatalysts synthesis via in situ oxidative free-radical polymerization of acrylonitrile (AN) using Alg@Ag nanoparticles (Alg@Ag NPs). Various analytical techniques, including FTIR, XRD, SEM, TEM, UV-Vis, and DSC, were employed to determine bonding interactions and chemical characteristics of the nanocatalyst. The optimized response surface methodology coupled central composite design (RSM-CCD) reaction conditions were a 35-min irradiation time in a 70- $\mathrm{mg} \mathrm{L}^{-1}$ 2,4-dinitrophenol (DNP) solution at $\mathrm{pH}$ of 4.68. Here, DNP degradation was $99.46 \%$ at a desirability of 1.00 . The pseudo-first-order rate constant $\left(K_{1}\right)$ values were $0.047,0.050,0.054,0.056,0.059$, and $0.064 \mathrm{~min}^{-1}$ with associated half-life $\left(t_{1 / 2}\right)$ values of $14.74,13.86,12.84,12.38,11.74,10.82$, and $10.04 \mathrm{~min}$ that corresponded to DNP concentrations of 10, 20, 30, 40, 50, 60, and $70 \mathrm{mg} \mathrm{L}^{-1}$, respectively, in the presence of PAN-g-Alg@Ag (0.03 g). The results indicate that the reaction followed the pseudo-first-order kinetic model with an $\mathrm{R}^{2}$ value of 0.99 . The combined absorption properties of PAN and Alg@Ag NPs on copolymerization on the surface contributed more charge density to surface plasmon resonance (SPR) in a way to degrade more and more molecules of DNP together with preventing the recombination of electron and hole pairs within the photocatalytic process.
\end{abstract}

Keywords: Ag nanoparticle; polymer nanocomposite; surface plasmon resonance; photocatalysis; Pesticides

\section{Introduction}

The environmental and economic impact of pollutants and toxic effluent on water quality has reached crisis levels and is detrimental to human and marine life [1]. Of the various carcinogenic compounds commonly found in water sources, nitrophenols and their derivatives are among the most harmful pollutants discharged from various pharmaceutical, agricultural, manufacturing, and steel production industry processes [2,3]. 2,4-Dinitrophenol (DNP), which belongs to a class of water-soluble alkyl dinitrophenols that are volatile in steam [4], is a particularly lethal carcinogen linked to restricted cell growth even at concentrations of $1 \mathrm{ppm}$, causing skin allergies and hyperthermia [5]. According to USEPA, DNP is part of a list of "priority pollutants" with a permissible limit of $10 \mathrm{mg} \mathrm{L}^{-1}$; DNP is acidic at a pKa value of 4.03 [6]. Given its devastating effects to both human health and the environment, researchers are keen to find effective, economical methods to remove DNP from water sources. None of the numerous reported physical and chemical procedures for the sequestration of phenolic pollutants, 
including strategies based on precipitation, ion exchange, adsorption, and disinfection, have effectively removed DNP from water sources, as most require unacceptably long reaction times, are expensive, or are destructive [3-5]. Photodegradation, which is the oxidation and fragmentation of organic molecules into small non-toxic moieties under the aegis of solar light at UV or visible wavelengths, has been proposed as a sophisticated and efficient method for overcoming the shortcomings of the above-mentioned procedures [6]. Photocatalytic degradation of organic pollutants using solar irradiation is extremely economical compared to the other physical and chemical processes using artificial UV radiation, as it circumvents the need for electric power input [6,7]. Photocatalytic degradation is extremely useful for water remediation processes and the purification of wastewater because it results in the complete mineralization of the organic pollutants to generate harmless inorganic compounds $[8,9]$.

Interdisciplinary research teams are currently working to characterize the chemical and physical properties of metal-based nanoparticles for photocatalytic applications. These nanoparticles have become renowned for their ability to remove organic pollutants from wastewater thanks to their large surface area, high adsorption capacity, weakened resistance to diffusion processes, and rapid reaction times due to the speed with which equilibration with guest molecules is achieved $[10,11]$. Various metaland metal oxide-based nanocomposites, including $\mathrm{ZnO}$ [12], $\mathrm{CuO}$ [13], $\mathrm{TiO}_{2}$ [14], $\mathrm{Fe}_{3} \mathrm{O}_{4}$ [15], $\mathrm{SnO}_{2}$ [16], and $\mathrm{Ag}$ [17], have been utilized for the photocatalytic degradation of nitrophenols. In particular, silver (Ag) NPs are considered to be the most prevalent and effective noble metal nanoparticles due to their optical, electronic, thermal, medicinal, photocatalytic, and antibacterial properties [17]. Since Ag NPs fall in the metal category, the valence band (VB) and conduction band (CB) overlap [10]. Thus, in these cases, the photocatalytic properties of Ag NPs in visible light may emerge due to excitation of surface plasmon resonance (SPR), which is the manifestation of a resonance effect due to the interaction of conduction electrons of metal nanoparticles with incident photons. The interaction relies on the size and shape of the metal nanoparticles and on the nature and composition of the dispersion medium $[18,19]$. The high absorption property of Ag-based nanocomposites in the visible light region, together with preventing the recombination of electron and hole pairs within the photocatalytic process, has drawn enormous attention to the application of Ag NPs in the catalytic field [20]. Since these metal nanoparticles are also thermodynamically unstable due to agglomeration effects, a considerable effort was taken into consideration to functionalize Ag NPs using copolymer chains composed of alginate-co-polyacrylonitrile to facilitate more efficient charge transfer mechanisms, particularly for the degradation of DNP as part of a green chemistry approach to water purification. Alginate, an anionic biopolymer obtained from brown algae and bacteria, is comprised of L-guluronic acid $(\mathrm{G})$ and D-mannuronic $(\mathrm{M})$ residues that are directly linked by 1,4-glycosidic linkages [21]. According to the US Food and Drug Administration, alginate is known for its high gel porosity, biocompatibility, and stability in aqueous environments [22]. Poly(acrylonitrile) (PAN) is a synthetic polymer extensively used in hot gas filtration systems and for the production of outdoor awnings, sails for yachts, and fiber-reinforced concrete due to its supreme physical qualities, commercial availability, and environmental stability [23]. Studies have shown that PAN can be employed for photocatalytic degradation reactions at maximum irradiation power intensity over $2-6 \mathrm{~h}$ [24]. PAN is a readily available, inexpensive polymer that exhibits high thermal stability, making it the ideal supporting material for copolymerization with alginate to generate a matrix platform that can be embedded with silver nanoparticles. The experimental results suggest enhanced physical, chemical, and morphological properties of PAN-g-Alg@Ag compared to the individual constituents.

Response surface methodology (RSM) is recognized worldwide as the best statistical and mathematical tool for optimizing reaction parameters with good precession and high desirability values [25]. In addition to its use in various applications for the production of biological hydrogen and acetic acid during the acidogenesis of wastewater, bacterial growth, and enzyme synthesis, RSM is sequentially applied for azo dye decolorization and photodegradation processes via the implementation of biological and physicochemical techniques [26]. RSM reduces the need for replicating experiments during optimization studies [27]. Since the goal of the current study was to find the most efficient method for the photodegradation of DNP in wastewater under direct solar irradiation using synthesized 
PAN-g-Alg@Ag NC, the application of RSM in our study was particularly useful for optimizing the aforementioned reaction.

\section{Materials and Methods}

\subsection{Chemicals}

Sodium alginate ( $200 \mathrm{kDa}, \mathrm{Na}^{+} 10 \%$ ) and acrylonitrile (AN, $\left.99 \%\right)$ were acquired from Merck $\mathrm{Co}$. Mumbai, India. 2,4-Dinitrophenol (DNP, $\left.\mathrm{C}_{6} \mathrm{H}_{4} \mathrm{~N}_{2} \mathrm{O}_{5}>98 \%\right)$ and silver nitrate $\left(\mathrm{AgNO}_{3}, \mathrm{ACS}\right.$ reagent $\left.>99.0 \%\right)$ were obtained from Sigma-Aldrich, Bangalore, India. All chemicals were used without any further modification, purification, or distillation. Deionized water (DI) was used for all experiments.

\subsection{Synthesis of the PAN-g-Alg@Ag Nanocomposite Material}

The synthesis of the respective materials was conducted using a previously reported protocol, but with some modifications $[28,29]$. Briefly, a solution containing $3.5 \%(w / v)$ alginate was added to a solution of $\mathrm{AgNO}_{3}(0.07 \mathrm{M})$ in DI water $(100 \mathrm{~mL})$, and the resulting mixture was stirred at $8000 \mathrm{rpm}$ and $298 \mathrm{~K}$ for $5 \mathrm{~h}$. The color of the mixture slowly became pale yellow, indicating the occurrence of nucleation of the Ag NPs supported by alginate side chains. An aliquot of the acrylonitrile monomer $(15 \mathrm{~mL})$ with a stoichiometric quantity of the $\mathrm{N}, \mathrm{N}$-methylene bisacrylamide (MBA) crosslinker $(0.50 \mathrm{~g})$ was added to the Alg@Ag suspension at $338 \mathrm{~K}$. After $2 \mathrm{~h}$ of vigorous mixing, $20 \mathrm{~mL}$ of a $3 \%(w / v)$ ammonium persulfate solution were added dropwise to initiate the in-situ polymerization of AN. The post-polymerization reaction was stirred for an additional $5 \mathrm{~h}$ before quenching protocols were conducted using excess $0.15 \mathrm{M}$ ferrous ammonium sulfate. The resulting milky white precipitate was collected via filtration and washed with an excess amount of DI water to remove any unreacted starting materials. Next, the precipitate was dried in a hot air oven at $323 \mathrm{~K}$ for $5 \mathrm{~h}$ before being stored for future photocatalytic experiments and characterization analysis.

\subsection{Analytical Techniques Used for Product Characterization}

The crystal structure and properties of the product polymer was determined using FTIR, XRD, transmission electron microscopy (TEM), energy dispersive X-ray (EDX), scanning electron microscopy (SEM), and differential scanning calorimetry (DSC). The type of bonding interactions and functional groups present in the nanocatalyst was determined via Fourier-transform infrared spectroscopy (FTIR) using a Perkin Elmer PE1600 spectrometer (USA). FTIR analysis was conducted in the $400-4000 \mathrm{~cm}^{-1}$ frequency range with the transmission mode. A Rigaku Ultima $1 \mathrm{~V}$ XRD diffractometer was employed to assess the crystalline structure of the nanocomposites. TEM was used to determine the particle size of the nanocomposites. Here, the elemental size and dispensation of the nanocomposite materials in the blended polymer matrix were determined using a JEM 2100 electron microscope (Japan). The surface morphological features, elemental identification, and both the chemical composition and homogeneity of PAN-g-Alg@Ag were determined via SEM combined with EDX (SEM; JEOL GSM 6510LV, Japan). DSC was conducted using a Mettler Toledo DSC822e calorimeter to determine the heat capacity and the enthalpies of crystallization and fusion; this allowed us to establish the thermal stability of the product nanocomposite. A Shimadzu UV-1900 UV-Vis double-beam spectrophotometer was utilized to analyze aliquots of the DNP samples after completion of the photocatalytic reaction.

\subsection{Photocatalytic Experiments}

The photocatalysis of the prepared samples was executed via the degradation of the DNP under direct solar irradiation at $25{ }^{\circ} \mathrm{C}$. Briefly, $0.03 \mathrm{~g}$ of PAN-g-Alg@Ag was dispersed in $20 \mathrm{~mL}$ of the DNP solution $\left(70 \mathrm{mg} \mathrm{L}^{-1}\right)$ under direct solar irradiation for $35 \mathrm{~min}$ to facilitate equilibration on the photocatalyst's surface for degradation process. The final concentration of DNP after completion of 
the degradation process was quantified using a UV-Vis spectrophotometer at maximum wavelength of $317 \mathrm{~nm}$ and was expressed by the following equation:

$$
\% \text { Degradation }=\frac{C_{o}-C_{t}}{C_{o}} \times 100
$$

where $C_{o}$ and $C_{t}$ are the concentrations of DNP before and after photodegradation.

\section{Results and Discussion}

\subsection{Characterization of the Synthesized Nanocomposite}

The FTIR spectra of PAN-g-Alg@Ag and its discrete elements are shown in Figure 1. The FTIR spectrum of sodium alginate (Figure 1a) shows peaks at $3411 \mathrm{~cm}^{-1}$ (-OH stretching), $2945 \mathrm{~cm}^{-1}$ (aliphatic $-\mathrm{CH}_{2}$ stretching), $1614-1420 \mathrm{~cm}^{-1}$ (symmetric and asymmetric $-\mathrm{COO}^{-}$stretching), and $1012 \mathrm{~cm}^{-1}$ (pyranoid C-O-C stretching) [30]. The FTIR spectrum of the Alg@Ag NPs (Figure 1b) contains a peak at $575 \mathrm{~cm}^{-1}$ that corresponds to the Ag-O coordination bond, whereas the peak at $3430 \mathrm{~cm}^{-1}$ is due to $-\mathrm{OH}$ stretching and $\mathrm{C}=\mathrm{O}$ bond stretching is evident in the peak at $1644 \mathrm{~cm}^{-1}$ [31]. The spectrum of PAN (Figure 1c) exhibits a wide sharp peak at $3450 \mathrm{~cm}^{-1}$ that is attributed to $-\mathrm{OH}$ groups due to humidity; the peak at 2246 $\mathrm{cm}^{-1}$ confirms the presence of nitrile groups $(-\mathrm{C}=\mathrm{N})$; peaks are noted at $1449-1624 \mathrm{~cm}^{-1}\left(-\mathrm{CH}\right.$ and $-\mathrm{CH}_{2}$ vibrations), $1061 \mathrm{~cm}^{-1}$ (-C-CN bond stretching), and $2926 \mathrm{~cm}^{-1}$ (stretching vibration of the $-\mathrm{CH}_{2}$ group of the PAN chain) [32]. The spectrum of PAN-g-Alg@Ag NC (Figure 1d) contains peaks at $3353 \mathrm{~cm}^{-1}$ (both $-\mathrm{OH}$ and $-\mathrm{NH}$ stretching) and $1634 \mathrm{~cm}^{-1}$ (-C=O bond). The peak at $575 \mathrm{~cm}^{-1}$ is due to the $\mathrm{Ag}-\mathrm{O}$ coordination bond, while peaks within the range of $1168-1381 \mathrm{~cm}^{-1}$ are attributed to the symmetric and asymmetric $-\mathrm{COO}^{-}$stretching of the alginate backbone. The reduced intensity of the peak associated with the nitrile functionality $\left(2246 \mathrm{~cm}^{-1}\right)$ is an indication of copolymerization between PAN and Alg rather than evidence of homo-polymerization of acrylonitrile [33,34].

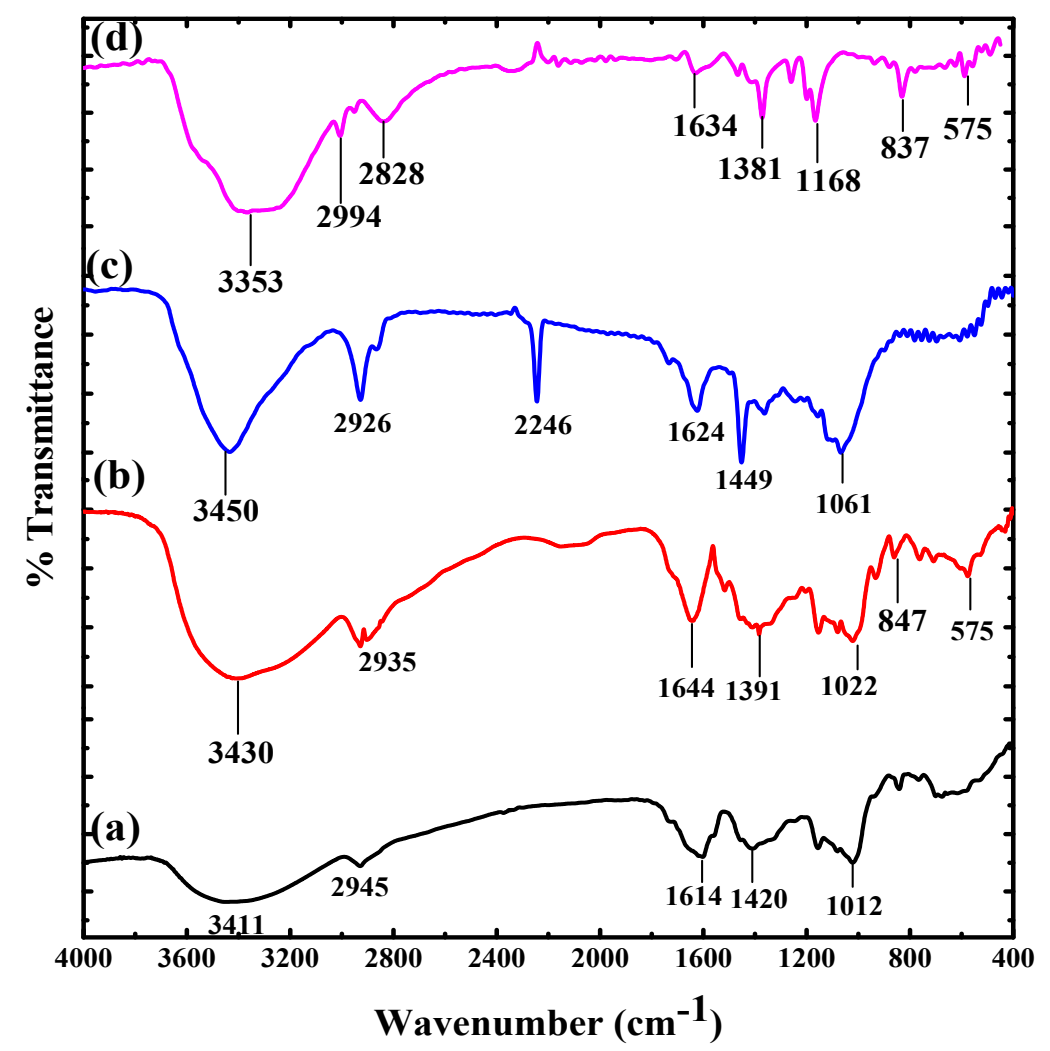

Figure 1. FTIR spectra of: (a) sodium alginate; (b) Alg@Ag NPs; (c) poly(acrylonitrile); and (d) PAN-g-Alg@Ag. 
Figure 2 displays the XRD spectra of PAN-g-Alg@Ag and its discrete components, providing information about the nanocomposite's crystalline structure. The XRD pattern of the Alg@Ag NPs shows $2 \theta$ values of $37.11^{\circ}, 43.32^{\circ}$, and $63.54^{\circ}$, corresponding to Miller indices of (200), (211), and (222), respectively, for the various planes of Alg@Ag NPs [35]. The XRD pattern shows that PAN is amorphous. The XRD spectrum of PAN-g-Alg@Ag contain all peaks associated with Alg@Ag NPs at $28.83^{\circ}$ (from PAN), $37.24^{\circ}, 43.44^{\circ}$, and $73.99^{\circ}$ with the corresponding Miller indices of (200), (211), and (203), thereby indicating that the Alg@Ag NPs successfully copolymerized with the PAN chains.

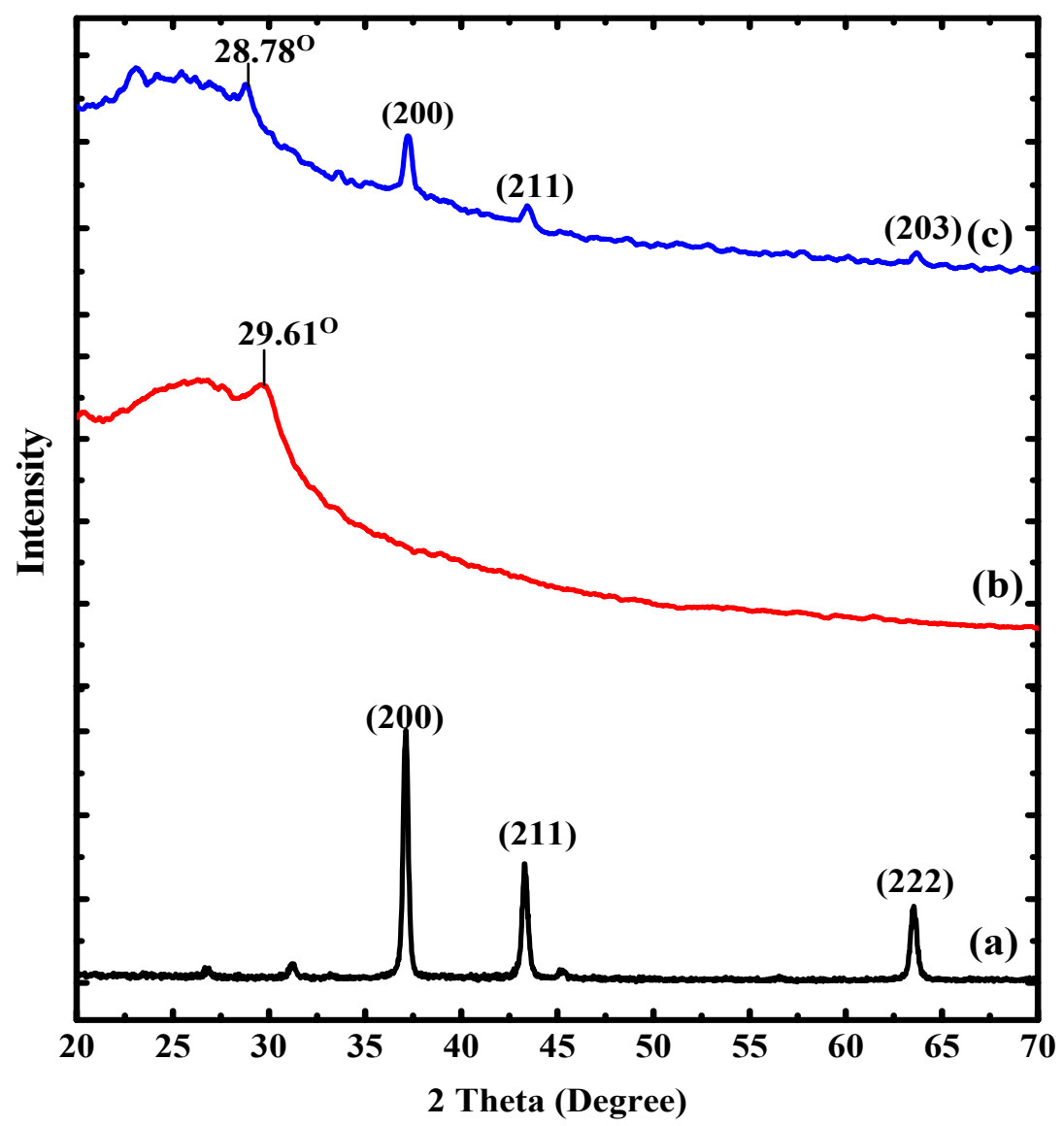

Figure 2. XRD spectra of: (a) Alg@Ag NPs; (b) poly(acrylonitrile); and (c) PAN-g-Alg@Ag.

Further information about the crystalline size cab was obtained using Scherer's formula: [36]

$$
\begin{gathered}
\mathrm{D}=\frac{0.9 \lambda}{\beta \cos \theta} \\
\text { Dislocation Density }(\delta)=\frac{1}{D^{2}} \\
\text { Interlayer Spacing }\left(\mathrm{d}_{200}\right)=\frac{n \lambda}{2 \operatorname{Sin} \theta} \\
\% \text { Crystallinity }=\frac{\text { Area under the crystalline peaks }}{\text { Total area }} \times 100
\end{gathered}
$$

where $D$ is the crystal's size, $\lambda$ is the wavelength used (i.e., $1.54 \mathrm{~A}^{\circ}$ ), $\beta$ is the half-width of the most intense peak, and $\theta$ is the angle of diffraction. Equation (2) reveals that the average crystal size in both Alg@Ag NPs and PAN-g-Alg@Ag was around 20 and 8 nm, respectively. As noted in Figure 2, there is a great compression in the peak width and intensity due to the functionalization of Alg@Ag NPs with PAN. These interactions are vital for facilitating variations of the d-spacing and lattice distortions 
during aggregation, resulting in additional size compressions from 20 to $8 \mathrm{~nm}$ after functionalization. The XRD data show that the surface of Alg@Ag NPs has been successfully modified by the PAN polymer blend, resulting in well-dispersed, semi-crystalline solids with adequate functional density.

Table 1 shows the diffraction angle, FWHM, interlayer spacing, crystal size, dislocation density, and percent crystallinity of the pure, functionalized Alg@Ag NPs. Generally, PAN-g-Alg@Ag NC has smaller crystals $(17.48 \mathrm{~nm})$ and large dislocation density $\left(3.27 \times 10^{16}\right)$ lines $\left(\mathrm{m}^{-2}\right)$ at the $(200)$ peak. The dislocation density $(\delta)$ is a measure of the number of defects in a crystal and is expressed in lines per meter square. The peak width and intensity of the product varies significantly depending on the extent of functionalization in the Alg@Ag NPs. The change in crystallinity from 52\% for Alg@Ag NPs to 19\% for the PAN-g-Alg@Ag nanocomposite is evidence of the copolymerization of Alg@Ag NPs by PAN chains.

Table 1. XRD parameters of Ag NPs associated with the Alg and PAN-g-Alg copolymer matrix.

\begin{tabular}{ccccccc}
\hline Component & $\mathbf{2 \theta}$ & $\begin{array}{c}\text { FWHM } \\
\left(\boldsymbol{\beta}_{\mathbf{h k l}}\right)\end{array}$ & $\begin{array}{c}\text { Interlayer } \\
\text { Spacing } \\
\left(\mathbf{d}_{\mathbf{2 0 0}}\right)\left(\mathbf{A}^{\circ}\right)\end{array}$ & $\begin{array}{c}\text { Size of } \\
\text { Crystal }(\mathbf{n m}) \\
\text { at }(\mathbf{2 0 0})\end{array}$ & $\begin{array}{c}\text { Dislocation } \\
\text { Density }(\boldsymbol{\delta}) \times \\
\mathbf{1 0}^{\mathbf{1 5}} \text { Lines }\left(\mathbf{m}^{-\mathbf{2}}\right)\end{array}$ & $\begin{array}{c}\text { \% } \\
\text { Crystallinity } \\
(\mathbf{\%})\end{array}$ \\
\hline Alg@Ag NPs & 37.11 & 0.33 & 0.26 & 25.39 & 1.55 & 52 \\
PAN-g-Alg@Ag NC & 37.24 & 0.48 & 0.24 & 17.48 & 3.27 & 19 \\
\hline
\end{tabular}

The surface morphology of PAN-g-Alg@Ag was determined via SEM analysis, as illustrated in Figure 3a-d. Figure 3a represents the SEM image of alginate showing crystalline dots across the plating surface at $2 \mu \mathrm{m}(\times 6000$ magnification). The surface of PAN (Figure $3 \mathrm{~b})$ appears to be fuzzy and fibrous at $2 \mu \mathrm{m}$ ( $\times 6000$ magnification). After the copolymerization of PAN and Alg@Ag NPs, as shown in Figure $3 \mathrm{c}$ at $5 \mu \mathrm{m}(\times 5000$ magnification $)$, PAN's morphology appeared porous with embedded granules. The SEM images confirmed the synthesis of PAN-g-Alg@Ag. Figure 3d displays the EDX spectrum of PAN-g-Alg@Ag, providing information about the elemental identification, chemical composition, and chemical homogeneity of PAN-g-Alg@Ag. Here, the strong signals of the silver atoms are noted at $3.30 \mathrm{keV}$, which is consonant with the reported binding energy of Ag NPs in silver metallic nanocrystals [37]. The total elemental composition of PAN-g-Alg@Ag NC is given in Table 2 using the K-line spectrum.

The particle size and distribution inside the polymer's stacked/unstacked matrix are established by conducting TEM measurements (Figure 4) at 20 and $10 \mathrm{~nm}$ magnification (Figure 4a,b, respectively). Here, we note that the minute globular point groups are limited and seem to be finely dispersed throughout the PAN-g-Alg copolymer matrix. The TEM image shows chemical homogeneity due to the presence of the PAN-g-Alg copolymer, which is ultimately responsible for stabilizing and reducing the Ag NPs. In addition, the average particle size of the Ag NPs in the PAN-g-Alg copolymer matrix is $8 \mathrm{~nm}$, as determined via the Gaussian average particles size distribution curve given in Figure 4c,d. Elemental mapping analysis was utilized to analyze the atomic distribution share of individual atoms present in the PAN-g-Alg@Ag NC. The mapping images in Figure S1 reveal that the atomic share (\%) of $\mathrm{C}, \mathrm{O}, \mathrm{N}$, and $\mathrm{Ag}$ are 29.13, 37.64, 32.72 and 0.51 respectively.

Table 2. The EDX spectroscopic data of the PAN-g-Alg@Ag NC.

\begin{tabular}{cccc}
\hline Element & Mass $\%$ & Atom $\%$ & Binding Energy $(\mathrm{KeV})$ \\
\hline $\mathrm{C}$ & 24.03 & 29.13 & $0.26-0.29$ \\
$\mathrm{~N}$ & 36.21 & 37.64 & $0.44-0.46$ \\
$\mathrm{O}$ & 35.95 & 32.72 & $0.52-0.54$ \\
$\mathrm{Ag}$ & 3.80 & 0.51 & $3.00-3.20$ \\
\hline
\end{tabular}




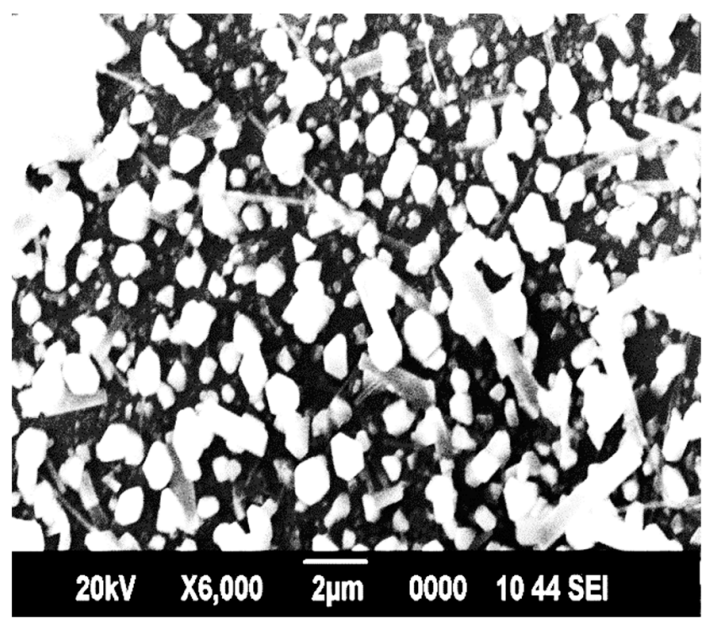

(a)

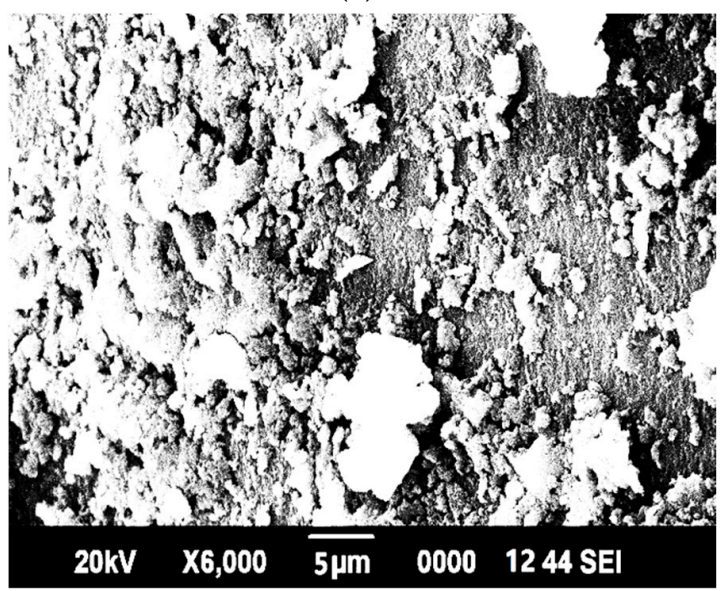

(c)

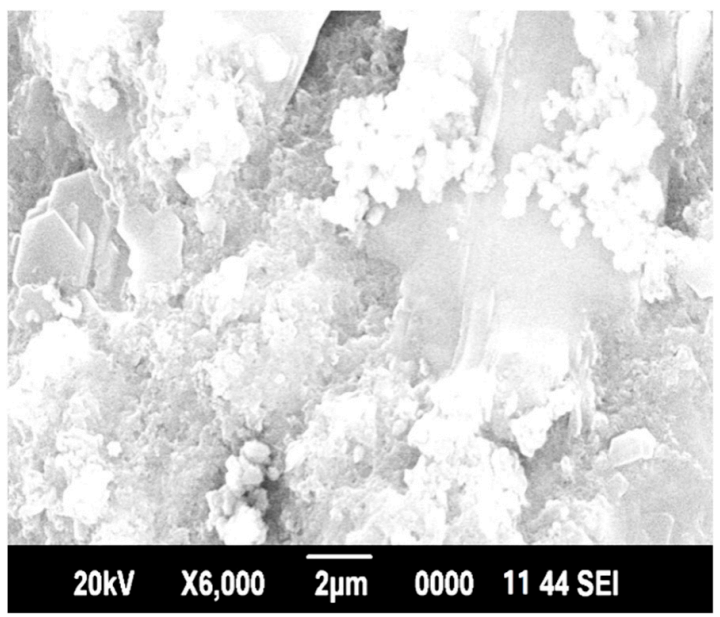

(b)

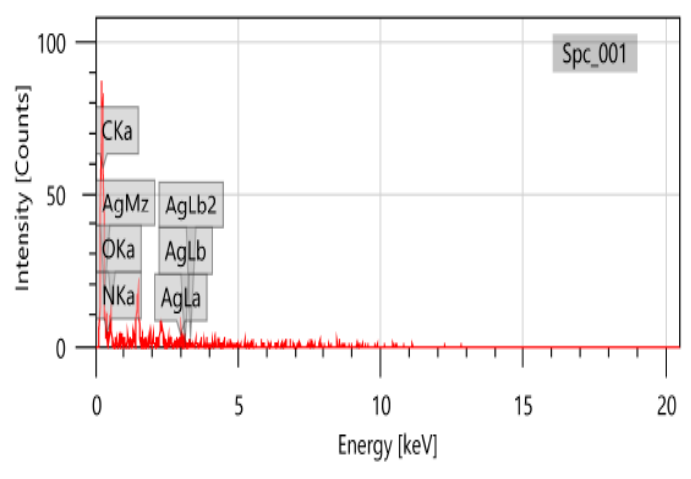

(d)

Figure 3. SEM images of: (a) sodium alginate; (b) poly(acrylonitrile); and (c) PAN-g-Alg@Ag. (d) The EDX spectrum of PAN-g-Alg@Ag.

The optical absorption properties of the alginate, PAN, Alg@Ag NPs, and PAN-g-Alg@Ag NC were determined via UV-Vis spectroscopy in the wavelength range 200-500 nm (Figure 5). The UV-Vis spectra of alginate exhibit a low peak at $279 \mathrm{~nm}$, while PAN shows negligible absorbance in the UV-Vis range. The spectra of Ag NPs synthesized through alginate sols show a remarkable absorbance peak at $433 \mathrm{~nm}$, which is due to complete reduction of $\mathrm{Ag}^{+}$ions into Ag NPs [38]. Further copolymerization of these Alg@Ag NPs with PAN chains resulted in a decrease in the magnitude of absorbance of Ag NPs, and a shift in the maxima was observed at $450 \mathrm{~nm}$. Thus, a red shift in absorbance maxima from 433 to $450 \mathrm{~nm}$ with reduction in peak intensity suggested that the Alg@Ag NPs were successfully functionalized by PAN chains. The alignment of the absorbance maxima in the visible region suggested that the nanocomposite material may utilize the visible solar light more efficiently in photocatalytic reactions [10]. The photocatalytic activities of Ag NPs evolve out of excitation of SPR (surface plasmon resonance), which is simply a collection of oscillating surface electron gas propagating at the interface of metal and dielectric medium [20]. 


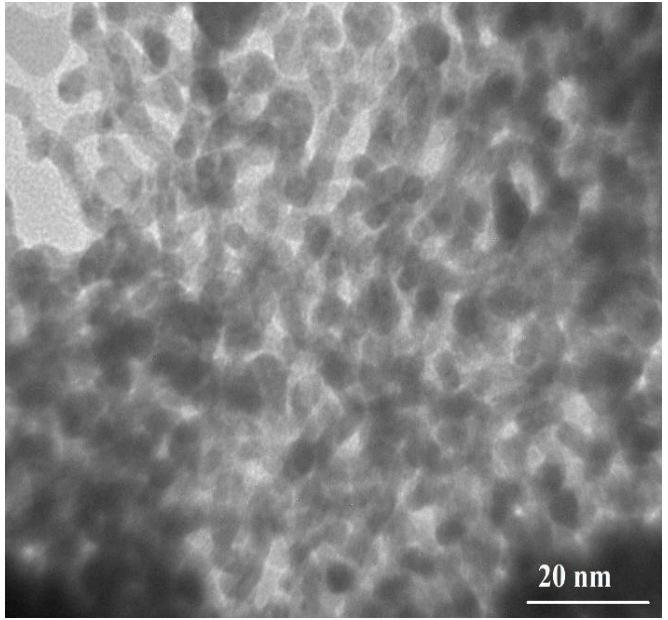

(a)

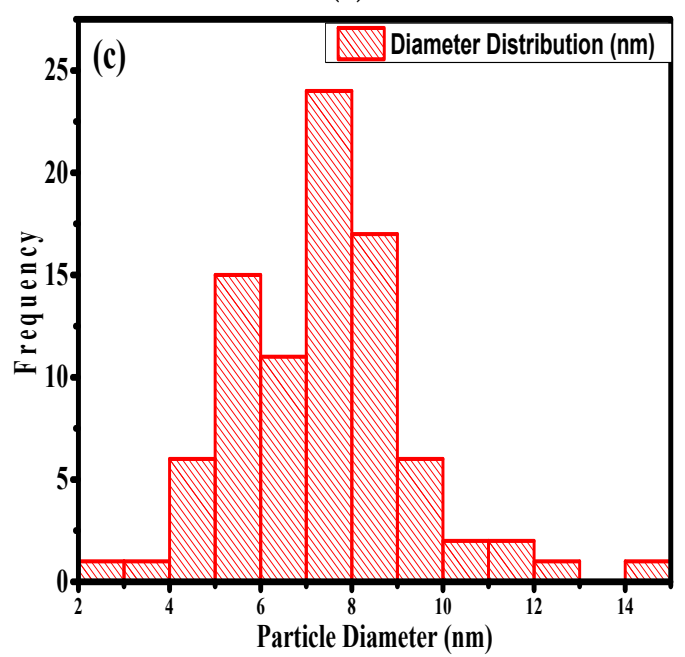

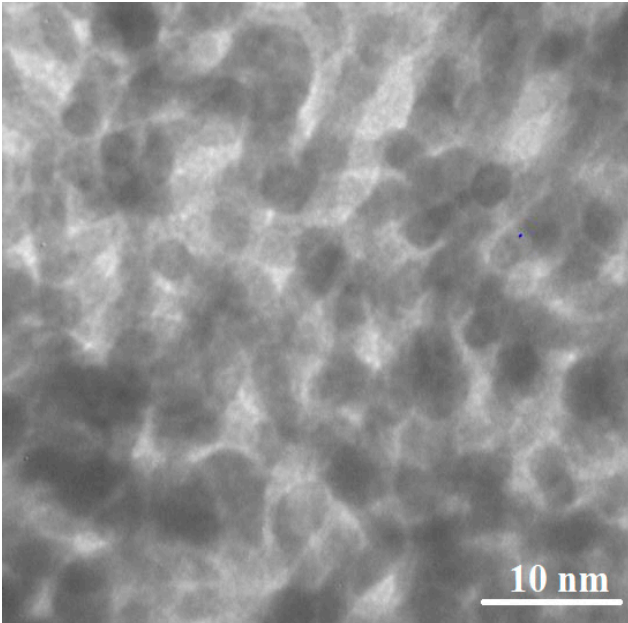

(b)

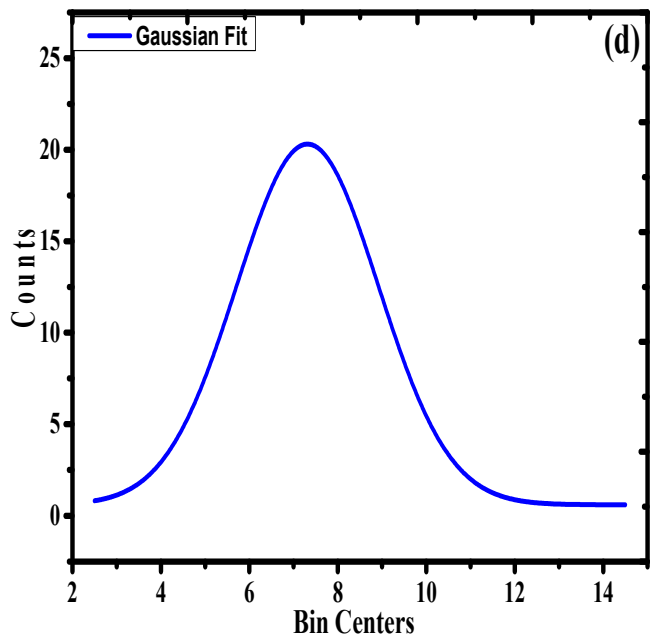

Figure 4. TEM images of the PAN-g-Alg@Ag nanocomposite.

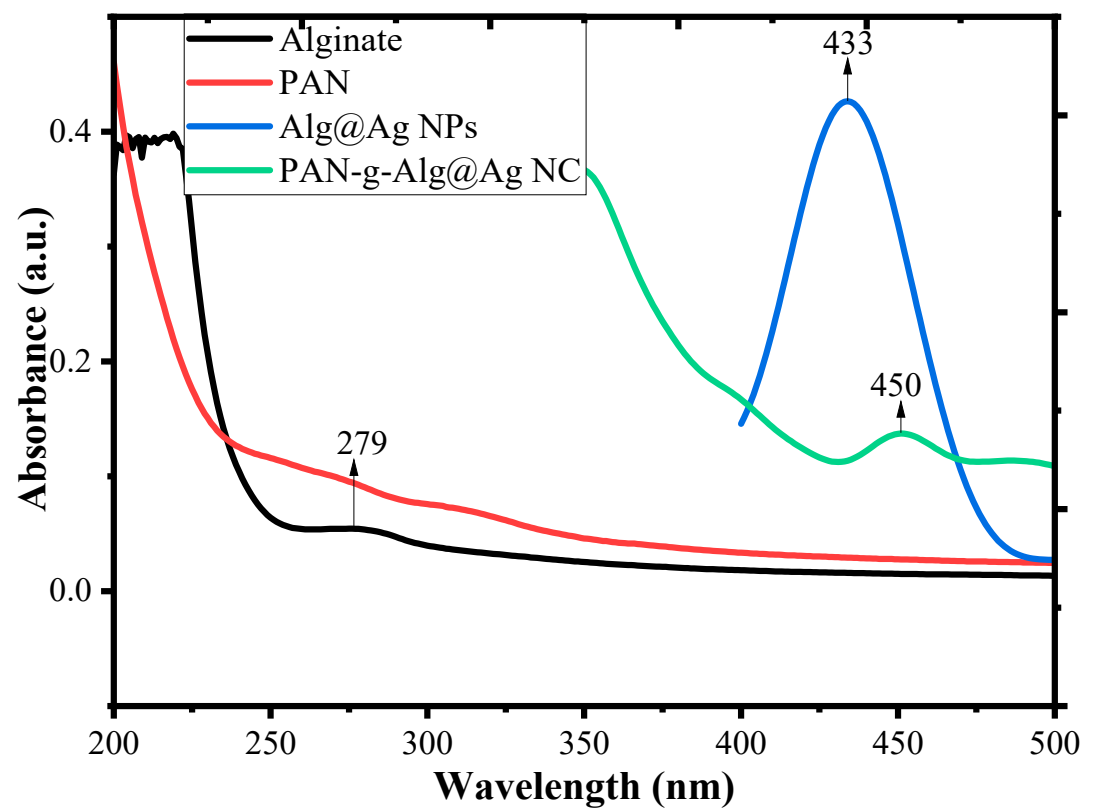

Figure 5. UV-Vis spectrum of alginate (black line), PAN (Red line), Alg@Ag NPs (blue line), and PAN-g-Alg@Ag NC (green line). 
DSC analysis is generally used to determine the thermodynamic stability of a compound by establishing various factors, including the glass transition temperature $\left(T_{g}\right)$ and the enthalpies of fusion or melting $\left(\Delta H_{F}\right)$ and crystallization $\left(\Delta H_{C}\right)$. The DSC profile of the nanocomposite material is given in Figure 6, and the inset contains an enlarged image of the selected area of analysis. The endothermic peak at $69^{\circ} \mathrm{C}$ is attributed to the glass transition temperature $\left(T_{g}\right)$ of the polymer matrix functionalized with Ag NPs. The initial and final melting temperatures of the material were 277 and $291^{\circ} \mathrm{C}$, respectively, which was due to the occurrence of cyclization reactions of the nitrile group $[34,38]$. The heat capacity $\left(C_{p}\right)$ at the initial reaction temperature was $12.94 \mathrm{~J} \mathrm{~g}^{-1}{ }^{\circ} \mathrm{C}^{-1}$. The enthalpy of fusion $\left(\Delta H_{F}\right)$ was $13.08 \mathrm{~J} \mathrm{~g}^{-1}$, whereas the enthalpy of crystallization $\left(\Delta H_{C}\right)$ was $4.53 \mathrm{~J} \mathrm{~g}^{-1}$.

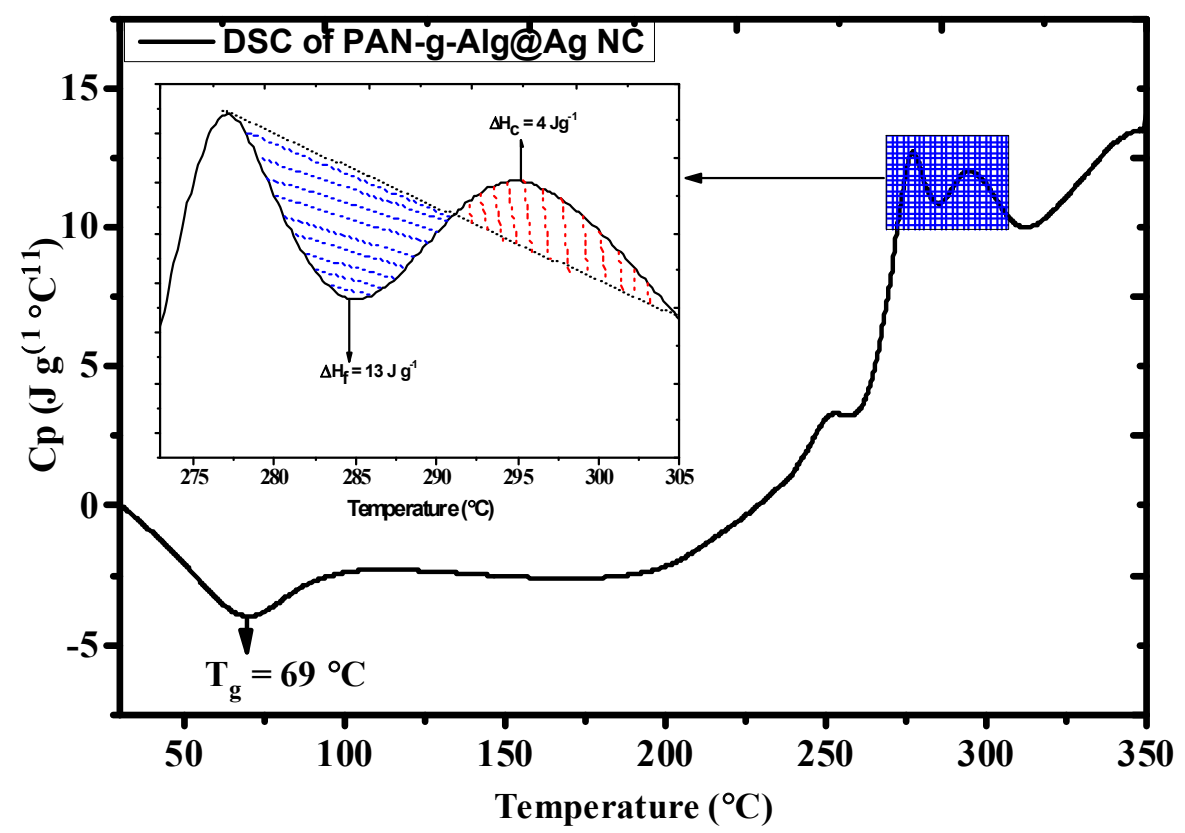

Figure 6. DSC spectrum of the PAN-g-Alg@Ag NCs.

\subsection{The RSM-Coupled Approach and Statistical Exploration}

Minitab17 software was utilized for conducting the experimental design that was subsequently executed via the RSM-coupled CCD to establish the synergistic or antagonistic effects of two or more variables on the response of the nanocomposite. The entire design mainly consisted of three parameters: irradiation time within the range of 10-35 $\mathrm{min}(\mathrm{A})$, a pH range of 1-5 (B), and the DNP concentration within the range of $20-70 \mathrm{mg} \mathrm{L}^{-1}$ (C). For the efficient degradation of DNP using PAN-g-Alg@Ag, the above-mentioned variables can be articulated using the quadratic regression equation:

$$
y=b_{0}+\sum_{i=1}^{n} b_{i} x_{i}+\sum_{i=1}^{n} b_{i i} x_{i}^{2}+\sum_{1 \leq i<j}^{n} b_{i j} x_{i} x_{j}+\varepsilon
$$

where $x_{i}$ and $x_{j}$ represent the linear function that transforms the original actual values, $X_{i}-\alpha C_{i}, X_{i}-C_{i}$, $X_{i}, X_{i}+C_{i}$, and $X_{i}+\alpha C_{i}$, to the coded values $-\alpha,-1,0,+1$, and $\alpha$ :

$$
x=\frac{\left(X-x_{i}\right)}{C_{i}}
$$

As noted in Table S1, these three variables, namely the irradiation time (A) (10-35 min), DNP solution $\mathrm{pH}(\mathrm{B})(1-5)$, and DNP concentration (C) (20-70 mg L $\left.\mathrm{L}^{-1}\right)$, were selected based on primarily batch-based experiments. Table S2 shows the variable ranges with the incorporated experimental and theoretical photodegradation responses. The correlation between the experimental 
and theoretical responses using the quadratic equation allowed us to effectively optimize the required reaction variables. Quadratic regression modeling was employed to determine the responses of the respective coded values for the three variables, which, in turn, was based on the experimental and theoretical outcomes:

$$
\begin{gathered}
\% \mathrm{D}=108.20-0.43 \mathrm{~A}-1.21 \mathrm{~B}-0.20 \mathrm{C}+0.01 \mathrm{~A}^{2}-0.01 \mathrm{~B}^{2}+0.00 \mathrm{C}^{2} \\
-0.01 \mathrm{~A} \times \mathrm{B}+0.00 \mathrm{~A} \times \mathrm{C}+0.04 \mathrm{~B} \times \mathrm{C}
\end{gathered}
$$

In this equation, the positive sign indicates the occurrence of synergism, whereas the negative sign is indicative of an antagonistic effect. Equation (8) shows that all the parameters (i.e., A, B, and C) exert antagonistic effects that influence the efficiency of photodegradation [39].

\subsubsection{Analysis of Variance}

The statistical implication and interaction results of each term obtained from the quadratic model are manifested via the analysis of variance (ANOVA), as shown in Table 3. The respective coefficient terms and the significance of the regression model are evaluated by the $p$ and F values using Fisher's null hypothesis method. Here, increased applicability is associated with the quadratic relevance model, and each coefficient term is imposed by the small $p$ and large $\mathrm{F}$ value. The large $\mathrm{F}$ and small $p$ values confirm the model's appropriateness, as evidenced by the RSM-coupled CCD [40]. The condition proposed by Fisher $p>\mathrm{F}<0.05$ can be seen in Table 3 . Here, the reasonable $p>\mathrm{F}$ value of 0.0002 noted in the proposed quadratic regression model is statistically significant and relevant for the photocatalytic degradation of DNP on PAN-g-Alg@Ag NCs. Linear variable terms such as the irradiation time (A, $p>\mathrm{F}=0.001)$, the DNP solution's $\mathrm{pH}(\mathrm{B}, p>\mathrm{F}=0.032)$, and the DNP concentration $(\mathrm{C}, p>\mathrm{F}=0.026)$ are statistically significant. When only the statistically significant terms in Equation (8) are taken into consideration, we obtain Equation (9):

$$
\% \mathrm{D}=108.20-0.43 \mathrm{~A}-1.21 \mathrm{~B}-0.20 \mathrm{C}+0.01 \mathrm{~A}^{2}-0.01 \mathrm{~A} \times \mathrm{B}+0.04 \mathrm{~B} \times \mathrm{C}
$$

Table 3. Analysis of variance (ANOVA) for the photodegradation of DNP on PAN-g-Alg@Ag NC.

\begin{tabular}{cccccc}
\hline Source & $\mathbf{D}_{\mathbf{F}}$ & $\mathbf{A}_{\mathbf{d j}} \mathbf{S S}$ & $\mathbf{A}_{\mathbf{d j}} \mathbf{M S}$ & $\mathbf{F}$ Value & $\boldsymbol{p}>$ F Value \\
\hline Model & 9 & 8.48 & 0.94 & 0.44 & 0.00 \\
$\mathrm{~A}$ & 1 & 0.00 & 0.00 & 0.99 & 0.00 \\
$\mathrm{~B}$ & 1 & 0.45 & 0.45 & 0.21 & 0.03 \\
$\mathrm{C}$ & 1 & 1.03 & 1.02 & 0.48 & 0.03 \\
$\mathrm{~A}^{2}$ & 1 & 3.99 & 3.99 & 1.86 & 0.00 \\
$\mathrm{~B}^{2}$ & 1 & 0.00 & 0.00 & 0.00 & 0.98 \\
$\mathrm{C}^{2}$ & 1 & 0.75 & 0.75 & 0.35 & 0.57 \\
$\mathrm{~A} \times \mathrm{B}$ & 1 & 0.03 & 0.03 & 0.02 & 0.01 \\
$\mathrm{~A} \times \mathrm{C}$ & 1 & 0.06 & 0.06 & 0.03 & 0.87 \\
$\mathrm{~B} \times \mathrm{C}$ & 1 & 2.39 & 2.39 & 1.11 & 0.03 \\
Error & 10 & 21.51 & 2.15 & &
\end{tabular}

$\mathrm{A}$ (irradiation time), $\mathrm{B}$ (DNP solution $\mathrm{pH}), \mathrm{C}(\mathrm{DNP}$ concentration), $\mathrm{A} \times \mathrm{B}$ (irradiation time $\times \mathrm{DNP}$ solution $\mathrm{pH})$, $\mathrm{A} \times \mathrm{C}$ (irradiation time $\times \mathrm{DNP}$ concentration), $\mathrm{B} \times \mathrm{C}(\mathrm{DNP}$ solution $\mathrm{pH} \times \mathrm{DNP}$ concentration).

The amplitude of the design is estimated by associating the coefficients of $R^{2}$ and $R^{2}$ adj. Here, the ANOVA values for $R^{2}$ and $R^{2}$ adj are 0.91 and 0.87 , indicating that there is a correlation between the theoretical and experimental values of the photocatalyst's response.

\subsubsection{Interpretation of the 3D Surface Data and Interaction Curves}

The 3D surface designs are the graphic representations of the quadratic regression equation that describe the synchronous effect of two variables on the photodegradation reaction when the other 
variables are maintained. Figure 7a,b depicts the 3D surface interaction curve between the $\mathrm{pH}$ of the DNP solution and the irradiation time under direct solar irradiation when the other variable remains constant. Notably, both variables exhibit a gradual increase in the reaction time from 10 to $45 \mathrm{~min}$, which is accompanied by the simultaneous increase in both the percent degradation from $95.22 \%$ to $99.80 \%$ and the $\mathrm{pH}$ of the solution from 1 to 5 . It can be inferred from the results in Figure 7a that long radiation times and high $\mathrm{pH}$ values favor the degradation of DNP by PAN-g-Alg@Ag NC. The reason behind this behavior may be attributed to the large number of active pore sites on the surface that facilitate extensive host-guest interactions. As the reaction proceeds, increasingly more active sites become engaged in the photodegradation of DNP, resulting in a higher percent degradation under longer irradiation times [3]. Since $\mathrm{pH} 4.0-5.0$ favors a high degradation capacity of $99.80 \%$, this may be interpreted as the competitive interaction for particular active sites on the photocatalyst's surface by both $\mathrm{H}^{+}$and phenolate ions at $\mathrm{pH}<4$; this is reflected in the pKa value of 2,4-DNP (4.4) under strongly acidic conditions. An increase in the $\mathrm{pH}$ from 1 to 5 also reduces the number of available $\mathrm{H}^{+}$ions, thereby allowing the maximum number of DNP molecules to interact with surface functional groups such as the cyano and hydroxyl moieties under direct solar irradiation. This, in turn, leads to a higher degradation capacity for the photocatalyst. At $\mathrm{pH}>5.0$, the presence of more negative ions generates repulsive forces between the negatively charged phenolate ions and the surface of the material, thereby decreasing the nanocomposite's photocatalytic capacity [41]. Figure $7 \mathrm{~b}$ shows the effects of increasing the DNP concentration from 20 to $70 \mathrm{mg} \mathrm{L}^{-1}$, which has the knock-on effect of increasing the photocatalyst's degradation capacity from $95.22 \%$ to $99.80 \%$. This improved catalytic efficiency facilitates the incorporation of increasingly more guest molecules through chemical interactions with the surface-active sites under direct solar irradiation. This, in turn, reinforces the principle that higher DNP concentrations favor improved percent degradation [42]. Figure 7c represents the interaction curve between the three operational variables, which follows the same trend observed above but with one notably different trait. Here, a rise in the DNP concentration simultaneously increases the nanocomposite's photodegradation capacity and the irradiation time. Similarly, the plot consisting of the solution's pH and the DNP concentration (i.e., 30, 45, and $60 \mathrm{mg} \mathrm{L}^{-1}$ ) shows a decrease in the nanocomposite's photodegradation capacity at $30 \mathrm{mg} \mathrm{L}^{-1}$, and a converse increase in the catalyst's photodegradation capacity at DNP concentrations of 45 and $60 \mathrm{mg} \mathrm{L}^{-1}$ with a simultaneous rise in the solution's $\mathrm{pH}$. This trend, observed at $30 \mathrm{mg} \mathrm{L}^{-1}$ of DNP, can be attributed to the availability of fewer DNP molecules for the active sites on the photocatalyst's surface, resulting in a reduction in the catalyst's photodegradation capacity. Figure $7 \mathrm{~d}$ portrays the normal probability plot obtained for the design validation system; it can also be argued that the points dispersed across the straight line represent no reaction exchange and manifest a distinctive appropriation curve [26]. The figure highlights the transference of points across the straight line with the approximation of $R^{2}$ and $R^{2}$ adj as 0.91 and 0.87 , respectively, thereby confirming the statistical validity of the model. The results obtained from the CCD model, which shows the three optimized variables after validation of the regression equation with a 95\% confidence interval, are a 35-min irradiation time (A), a $\mathrm{pH}$ value of 4.7 for the DNP solution (B), and a DNP concentration of $70 \mathrm{mg} \mathrm{L}^{-1}(\mathrm{C})$. The photocatalytic experiments using PAN-g-Alg@Ag NC in the presence of these optimized conditions gives a maximum of $99.56 \%$, which is close to the predicted value of $99.80 \%$ with a desirability value of $\mathrm{D}=1.00$. 


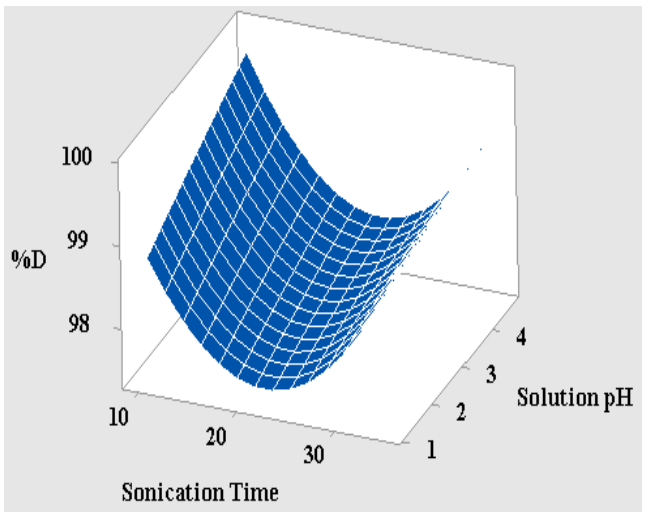

(a)

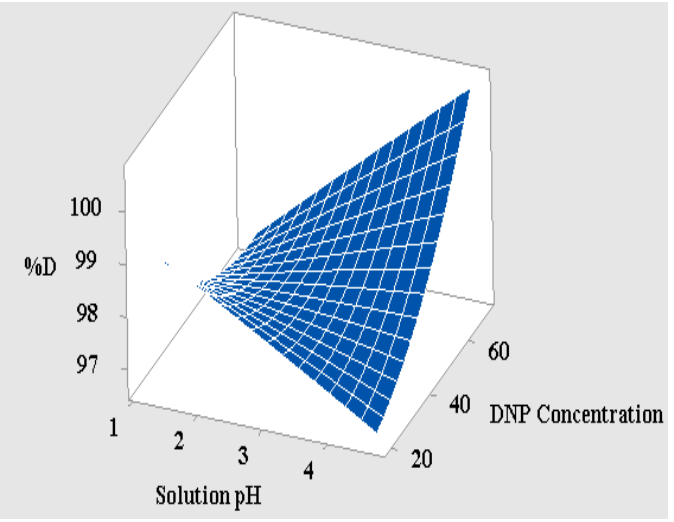

(b)

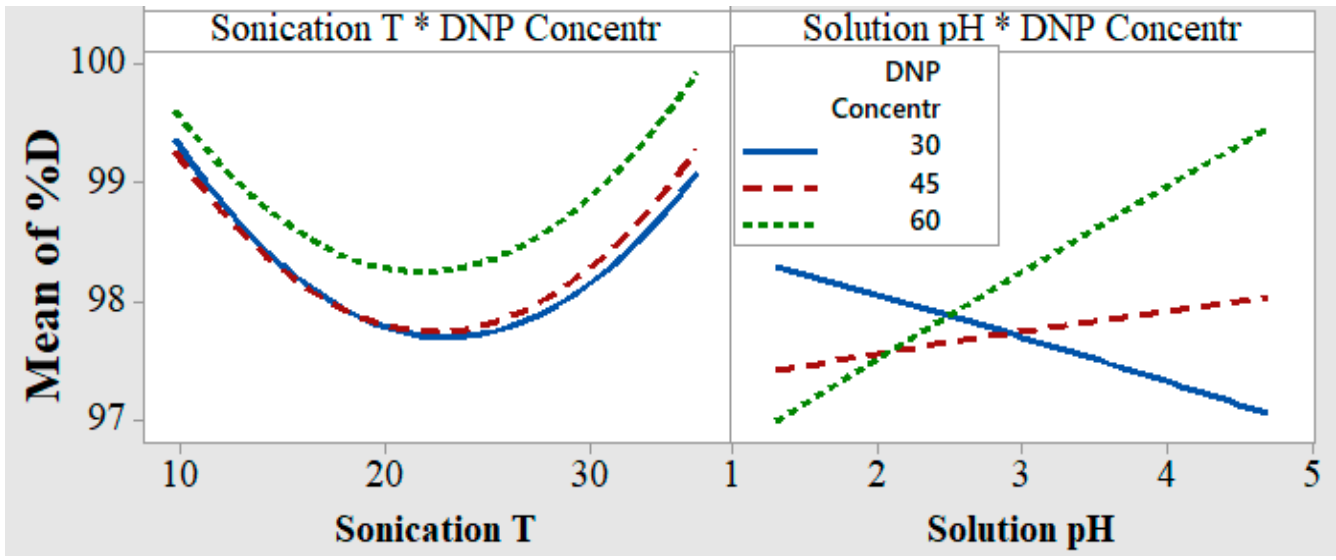

(c)

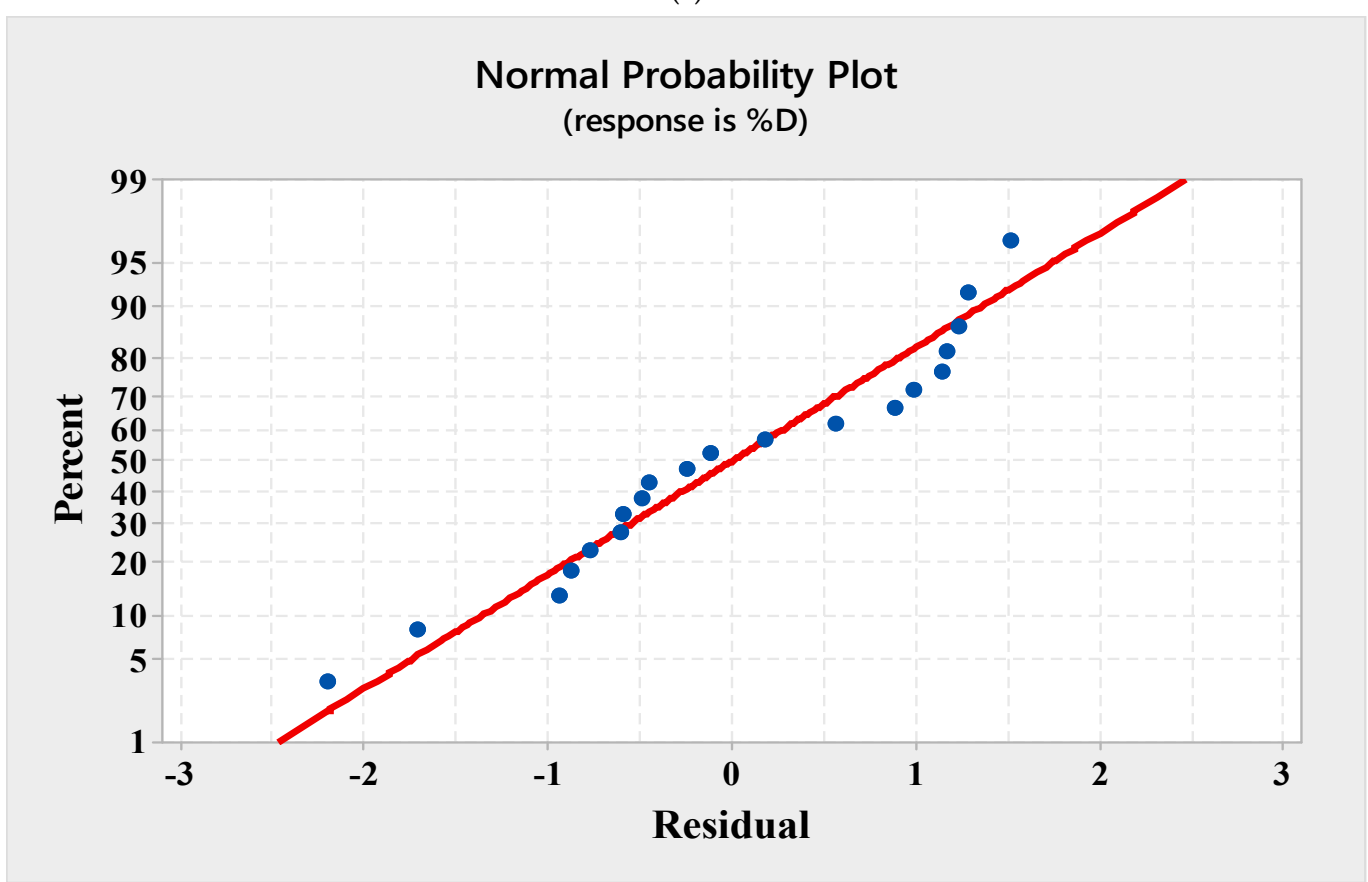

(d)

Figure 7. $(\mathbf{a}, \mathbf{b}) 3 \mathrm{D}$ surface interactive plot of the irradiation time vs. solution $\mathrm{pH}$ and a plot of the solution $\mathrm{pH}$ vs. the DNP concentration; (c) interaction curves of all three reaction variables, namely irradiation time, solution $\mathrm{pH}$, and DNP concentration; and (d) normal probability plot depicting the data points along the straight line. 


\subsection{Kinetics of Photodegradation}

The extent of the DNP photodegradation using the PAN-g-Alg@Ag NCs was investigated via UV-Vis spectroscopy of DNP $\left(70 \mathrm{mg} \mathrm{L}^{-1}\right)$ at the maximum absorbance of $317 \mathrm{~nm}$ (Figure 8a). The absorption spectra of the degraded 2,4-DNP aqueous solution during variable direct solar irradiation times in the presence of the photocatalyst is shown in Figure 8a. The absorbance peaks of DNP continuously decrease from an initial value of 0.083 at $5 \mathrm{~min}$ to 0.069 at $10 \mathrm{~min}, 0.058$ at $20 \mathrm{~min}$, 0.051 at $30 \mathrm{~min}, 0.045$ at $40 \mathrm{~min}$, and 0.041 at $50 \mathrm{~min}$, indicating a rise in the total photodegradation capacity from $92.90 \%$ at $5 \mathrm{~min}$ to $96.49 \%$ at $50 \mathrm{~min}$.
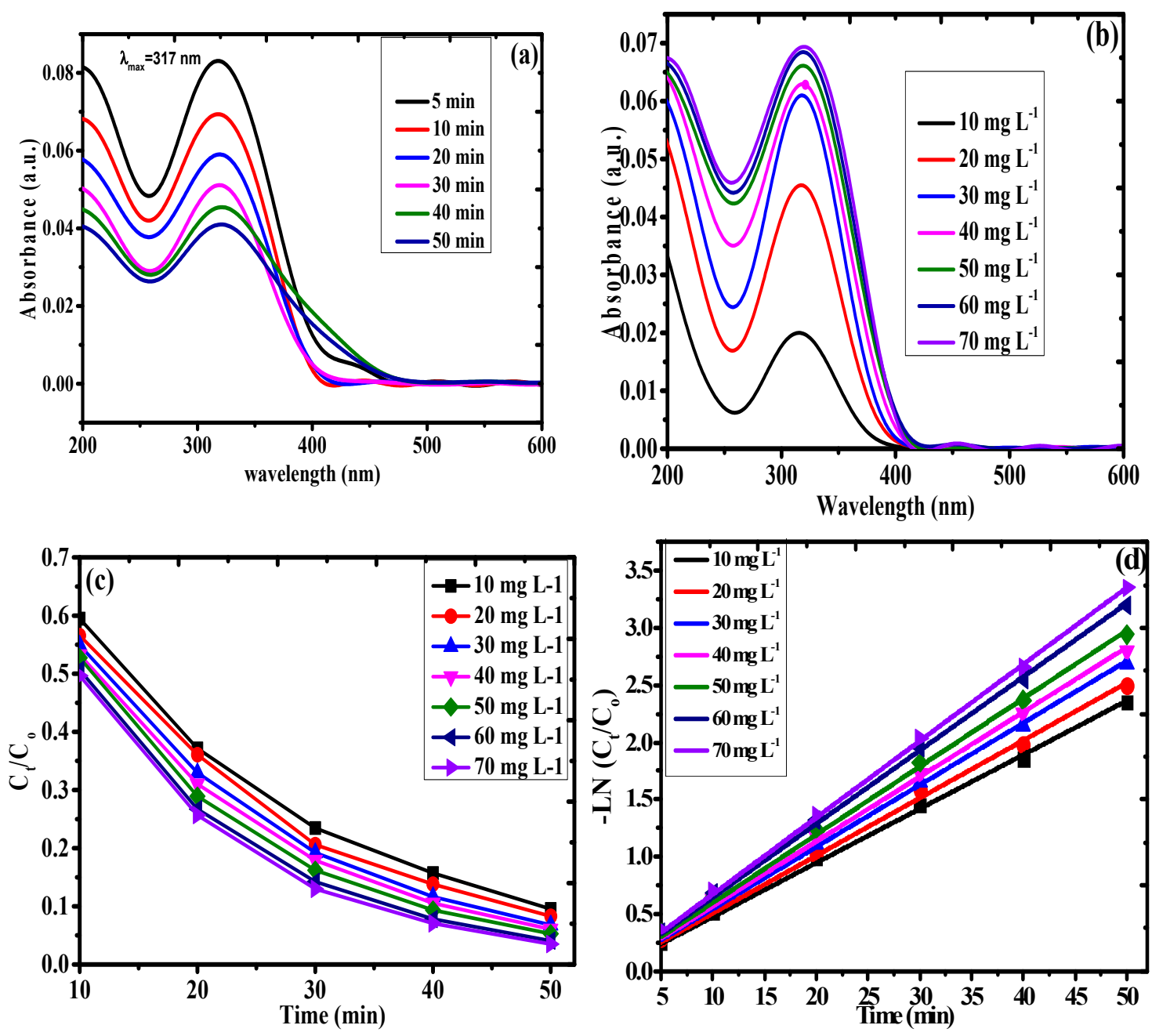

Figure 8. (a) UV-Vis action curve for irradiation time; (b) UV-Vis action curve for variable concentration of DNP; (c) Ce/Co vs. irradiation curve; and (d) pseudo-first order kinetic ci = curve for variable concentration of DNP.

Figure $8 \mathrm{~b}$ shows the absorbance spectra obtained using various concentrations of DNP ranging from 10 to $70 \mathrm{mg} \mathrm{L}^{-1}$ as a function of the irradiation time between 5 and $50 \mathrm{~min}$. In the figure, we note that successive increases in the irradiation time from 5 to $50 \mathrm{~min}$ and the concentration of DNP from 10 to $70 \mathrm{mg} \mathrm{L}^{-1}$ results in a gradual decrease in the absorbance peak of DNP. The total photodegradation capacity under the optimized irradiation time of 50 min changes from $87.86 \%$ at $10 \mathrm{mg} \mathrm{L}^{-1}$ to $94.68 \%$ at $70 \mathrm{mg} \mathrm{L}^{-1}$. Incremental changes in the irradiation time during photocatalysis facilitate faster reactions with a degradation potency of $94 \%$ within a 50 -min period.

Estimating the rate determining step in the kinetic experiments is vital for determining the reaction pathway in which the substrate adheres to the catalyst. The experimental evidence obtained from the 
pseudo-first-order kinetic model studies can be used to calculate the half-life periods and rate constants throughout the reaction [43]. Mathematically, this can be expressed as:

$$
\begin{gathered}
-\ln \left(\frac{C_{t}}{C_{0}}\right)=k t \\
t_{1 / 2}=\frac{0.693}{k}
\end{gathered}
$$

where $C_{o}$ represents the original concentration of DNP $\left(\mathrm{mg} \mathrm{L}^{-1}\right), C_{t}$ is the remnant concentration of DNP at time $t, k$ is the pseudo-first-order rate constant $\left(\mathrm{min}^{-1}\right)$, and $t_{1 / 2}(\mathrm{~min})$ represents the half-life of the reaction. Here, the concentration of DNP, i.e., 10, 20, 30, 40, 50, 60, and $70 \mathrm{mg} \mathrm{L}^{-1}$, is analyzed using the PAN-g-Alg@Ag NCs under the optimized reaction conditions. The results of the photodegradation studies are shown in Figure $8 \mathrm{c}$ as a plot of $C_{t} / C_{o}$ against the irradiation time. A comparable plot between $-\operatorname{Ln}\left(C_{t} / C_{o}\right)$ and the irradiation time $(\mathrm{min})$ is seen in Figure $8 \mathrm{~d}$. Here, the slope of the straight line represents the first-order rate constant $\left(K_{1}\right)$ as $0.047,0.050,0.054$, $0.056,0.059$, and $0.064 \mathrm{~min}^{-1}$, with half-life $\left(t_{1 \backslash 2}\right)$ values of $14.74,13.86,12.84,12.38,11.74,10.82$, and $10.04 \mathrm{~min}$, respectively, which correspond to 10, 20, 30, 40, 50, 60, and $70 \mathrm{mg} \mathrm{L}^{-1}$ of DNP with $0.03 \mathrm{~g}$ of PAN-g-Alg@Ag. The upgraded pseudo-first-order kinetic model, with an $\mathrm{R}^{2}$ value of 0.99 , is shown in Table 4. Thus, the outcome of these optimized experiments on the photocatalysis of DNP using PAN-g-Alg@Ag NCs is that incremental increases in the DNP concentration with respect to the irradiation time leads to gradual increases in the rate of photodegradation up to $35 \mathrm{~min}$. Beyond this point, the higher light absorbance of the DNP molecule in aqueous solution facilitates effective photodegradation on the surface of PAN-g-Alg@Ag. There is a noted light masking effect in the aqueous medium due to the increased number of DNP molecules that impede the absorption of light by the photocatalyst's surface [44]. The incremental increase in the magnitude of this masking effect generates the reactive radical $(\bullet H O)$ or electron-hole $\left(h_{v b}^{+}\right)$induced by excitation of SPR that subsequently degrades the DNP molecule. The rate determining step in this heterogeneous catalysis normally entails the adsorption of DNP onto the surface of the PAN-g-Alg@Ag NC and its degradation through the reactive $(\bullet \mathrm{HO}) /\left(h_{v b}^{+}\right)$species $[4,44]$. We deduce that the interference of the pathlength of the quantum of light during its interaction with the photocatalyst occurs as the DNP concentration increases, thereby retarding the rate of the degradation reaction. For an aliquot of DNP $\left(20 \mathrm{mg} \mathrm{L}^{-1}\right)$, the surface area of PAN-g-Alg@Ag required for efficient photodegradation can be easily calculated. As we move toward higher DNP concentrations, i.e., 40, 50, 60, and $70 \mathrm{mg} \mathrm{L}^{-1}$, the photodegradation process suffers from the limitations caused by a secondary layer of DNP molecules, which expands the duration of the irradiation parameter to facilitate the aggregation of the predominantly DNP molecular layer on the surface of the photocatalyst.

Table 4. Pseudo-first-order kinetic model for the photodegradation of DNP by PAN-g-Alg@Ag NC with the associated error analysis.

\begin{tabular}{cccccc}
\hline S.N. & $\begin{array}{c}\text { Concentration } \\
\left(\mathbf{m g ~ L}^{-\mathbf{1}}\right)\end{array}$ & $\begin{array}{c}\text { Rate Constant } \\
(\boldsymbol{K})\left(\mathbf{m i n}^{-\mathbf{1}}\right)\end{array}$ & $\begin{array}{c}\text { Half-Life } \\
\left(\boldsymbol{t}_{\mathbf{1 / 2}}\right)(\mathbf{m i n})\end{array}$ & $\mathbf{R}^{\mathbf{2}}$ & ${\mathbf{S S E ~}\left(\times \mathbf{1 0}^{-\mathbf{4}}\right)}$ \\
\hline 1 & 10 & 0.05 & 14.74 & 0.99 & 5.13 \\
2 & 20 & 0.05 & 13.86 & 0.99 & 6.79 \\
3 & 30 & 0.05 & 12.84 & 0.99 & 4.72 \\
4 & 40 & 0.06 & 12.38 & 0.99 & 5.54 \\
5 & 50 & 0.06 & 11.74 & 0.99 & 5.41 \\
6 & 60 & 0.06 & 10.82 & 0.99 & 3.81 \\
7 & 70 & 0.07 & 10.04 & 0.99 & 3.44 \\
\hline
\end{tabular}




\subsection{Photocatalytic Activity of PAN-g-Alg@Ag NC and Its Individual Entities}

Figure 9a,b represents the UV-Vis plot for the photocatalytic activity of synthesized PAN-g-Alg@Ag $\mathrm{NC}$ and its individual constituents towards DNP and corresponding percent degradation rate under solar light irradiation and optimized reaction conditions. It can be seen from the results that the synthesized material has maximum photocatalytic efficiency (96.32\%) as compared to its individual constituents of alginate (37.42\%), PAN (1.84\%), and Alg@Ag NPs (87.73\%). The enhanced photocatalytic activity of PAN-g-Alg@Ag NC may be due to combined absorption properties of PAN and Alg@Ag NPs, which on copolymerization on surface contributed more charge density to SPR in a way to degrade more and more molecules of DNP [19].
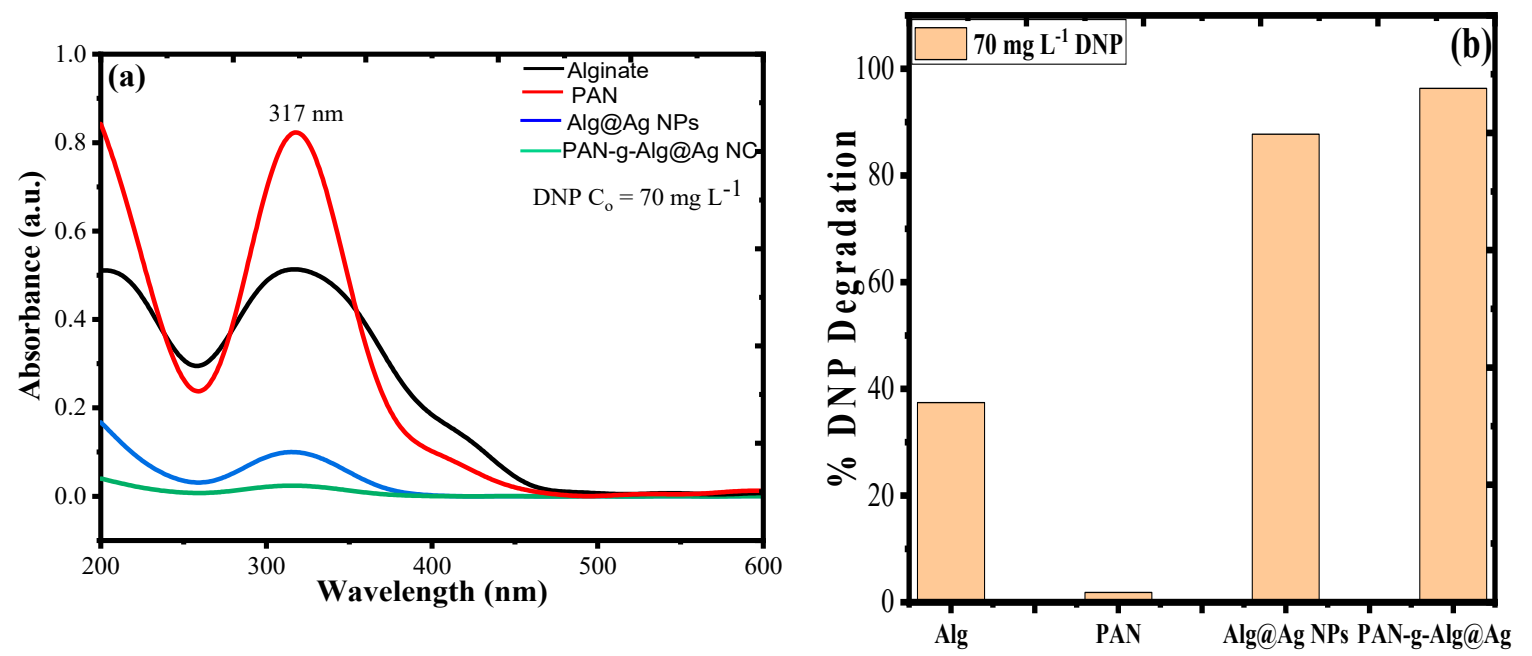

Figure 9. (a) UV-Vis plot for the photocatalytic activity of synthesized PAN-g-Alg@Ag NC and its individual constituents towards DNP; and (b) the corresponding percent degradation bar graph.

\subsection{Photocatalytic Degradation of DNP in Dark and Sunlight}

Figure 10a represents the UV-Vis plot and degradation rate of DNP in direct solar irradiation without catalyst (photolysis), dark with catalyst, and direct solar irradiation with catalyst. Figure 10b shows that the rate of DNP degradation without catalyst under direct solar irradiation (photolysis, A) was found to be $4.29 \%$, with catalyst in dark (B) was $47.23 \%$, and with catalyst in direct solar irradiation (C) was $97.56 \%$ for an aliquot of $20 \mathrm{~mL}$ of $70 \mathrm{mg} \mathrm{L}^{-1} \mathrm{DNP}$ under optimized reaction conditions. Since some part of DNP absorbs in visible region, which resulted in negligible degradation of DNP in direct solar irradiation without catalyst [45], a removal of $47.23 \%$ of DNP in the dark by catalyst was due to adsorption process. Since the catalyst is rich in surface functional $\mathrm{OH} / \mathrm{CN}$ groups, which can bond the DNP to surface of the catalyst by some kind of adsorption process at optimal $\mathrm{pH}$ conditions, the combination of DNP with catalyst under direct solar irradiation at optimized reaction conditions resulted in $97.56 \%$ DNP degradation, which was due to photocatalytic mineralization of DNP by excited SPR of Ag NPs functionalized by PAN-g-Alg polymer blend. 

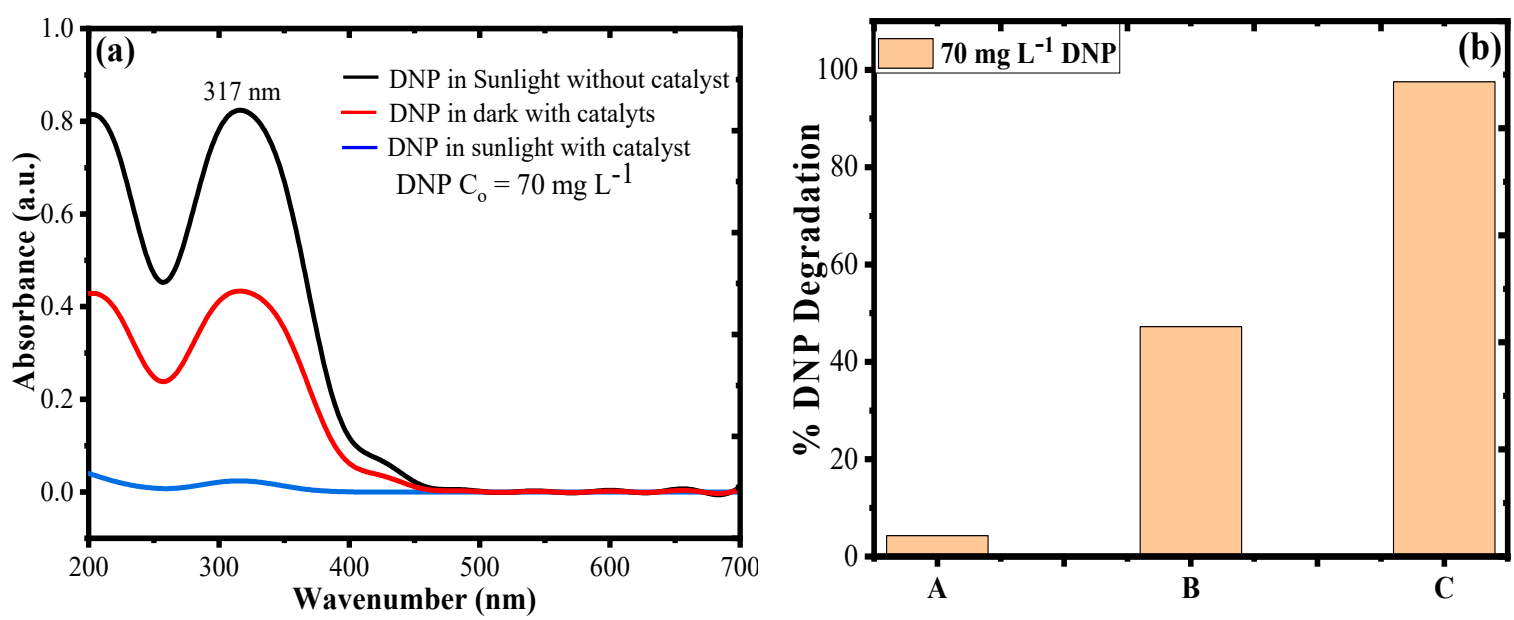

Figure 10. (a) UV-Vis plot; and (b) degradation rate of DNP in direct solar irradiation without catalyst (photolysis, A), dark with catalyst (B), and direct solar irradiation with catalyst (C) for an aliquot of 20 $\mathrm{mL}$ of $70 \mathrm{mg} \mathrm{L}^{-1} \mathrm{DNP}$ under optimized reaction conditions.

\subsection{Effect of Electrolyte Concentration on DNP Degradation}

Figure S2 represent the UV-Vis plot for the effect of electrolyte concentration $(\mathrm{NaCl})$ on the photocatalytic degradation of DNP under direct solar irradiation and optimized reaction conditions. The experiments were performed by taking $1-4 \mathrm{mM} \mathrm{NaCl}$ concentration with combination of DNP and catalyst. It can be seen that presence of electrolyte $\mathrm{NaCl}$ has very negligible antagonistic effect on the degradation of DNP as the results were $92.88 \%$ degradation at $1 \mathrm{mM} \mathrm{NaCl}, 93.01 \%$ degradation at $2 \mathrm{mM} \mathrm{NaCl}, 93.25 \%$ degradation at $3 \mathrm{mM} \mathrm{NaCl}, 94.64 \%$ degradation at $1 \mathrm{mM} \mathrm{NaCl}$, and $96.21 \%$ degradation in absence of $\mathrm{NaCl}$. Thus, with increase in salt concentration from 1-4 $\mathrm{mM}$, the DNP degradation efficiency reduces from $96.21 \%$ to $92.88 \%$.

\subsection{The Mechanism of Photodegradation}

Based on the data obtained through photocatalytic experiments for DNP degradation by PAN-g-Alg@Ag NC through excitation of SPR, a hypothesis was proposed to explain the type of mechanism involved in the photocatalytic degradation of DNP [46].

$$
\begin{aligned}
& \text { PAN-g-Alg@Ag + Solar irradiation } \rightarrow \text { PAN-g-Alg@Ag }\left(\mathrm{h}_{\mathrm{VB}}^{+}+\mathrm{e}_{\mathrm{CB}}^{-}\right) \\
& \text {DNP }+ \text { Solar irradiation } \rightarrow \text { DNP }^{*} \\
& \mathrm{DNP}^{*}+\text { PAN-g-Alg@Ag } \rightarrow \mathrm{DNP}^{\bullet+}+\text { PAN-g-Alg@Ag }\left(\mathrm{e}_{\mathrm{CB}}^{-}\right) \\
& \mathrm{O}_{2}+\text { PAN-g-Alg@Ag }\left(\mathrm{e}_{\mathrm{CB}}^{-}\right) \rightarrow \text { PAN-g-Alg@Ag }+\mathrm{O}_{2}^{\bullet-} \\
& \mathrm{O}_{2}^{\bullet-}+\mathrm{H}^{+} \rightarrow \mathrm{HO}_{2}^{\bullet} \\
& 2 \mathrm{HO}_{2}^{\bullet} \rightarrow \mathrm{O}_{2}+\mathrm{H}_{2} \mathrm{O}_{2} \\
& \mathrm{H}_{2} \mathrm{O}_{2}+\mathrm{O}_{2}^{\bullet-} \rightarrow \mathrm{HO}^{-}+\mathrm{HO}^{\bullet}+\mathrm{O}_{2} \\
& \mathrm{H}_{2} \mathrm{O}_{2}+\mathrm{e}^{-} \rightarrow \mathrm{HO}^{-}+\mathrm{HO}^{\bullet} \\
& \mathrm{H}_{2} \mathrm{O}+\text { PAN-g-Alg@Ag }\left(\mathrm{h}_{\mathrm{VB}}^{+}\right) \rightarrow \text { PAN-g-Alg@Ag }+\mathrm{HO}^{\bullet}+\mathrm{H}^{+} \\
& \mathrm{HO}^{-}+\text {PAN-g-Alg@Ag }\left(\mathrm{h}_{\mathrm{VB}}^{+}\right) \rightarrow \text { PAN-g-Alg@Ag }+\mathrm{HO}^{\bullet}
\end{aligned}
$$


The absorption of solar radiation on the surface of the PAN-g-Alg@Ag NC leads to excitation of SPR, which resulted in generation of charge carriers and transportation of electron and hole pairs $\left(\mathrm{e}^{-} \mathrm{CB} / \mathrm{h}^{+}{ }_{\mathrm{VB}}\right)$. From the UV-Vis absorption experiments, it was found that both PAN-g-Alg@Ag and DNP can absorb solar irradiation efficiently. When a combination of PAN-g-Alg@Ag + DNP was placed under direct solar irradiation of energy hv, PAN-g-Alg@Ag absorbed the photons and generated $\left(\mathrm{h}^{+} \mathrm{VB}+\mathrm{e}^{-} \mathrm{CB}\right)$ pair due to their high SPR effect (Equation (1)) [47]. The adsorbed DNP molecule on catalyst surface absorbed the solar irradiation and donated its photogenerated electron to conduction band (CB) of PAN-g-Alg@Ag (Equations (2) and (3)). The surface adsorbed oxygen $\left(\mathrm{O}_{2}\right)$ molecules in contact with these photogenerated electrons transformed into superoxide radical anions $\left(\mathrm{O}_{2}{ }^{\bullet-}\right)$ and hydrogen peroxide radicals $\left(\mathrm{HOO}^{\bullet}\right)$ (Equations (4)-(7)) [48,49]. As a result of SPR excitation, the photogenerated holes $\left(\mathrm{h}^{+} \mathrm{VB}\right)$ reacted with surface adsorbed water molecules $\left(\mathrm{H}_{2} \mathrm{O}\right)$ or hydroxyl anion $\left(\mathrm{OH}^{-}\right)$to transform them into hydroxyl radicals $(\mathrm{HO})^{\bullet}$ [49]. These photogenerated active radical species then attacked the DNP molecule to mineralize it to nontoxic entities. The possible mechanism for degradation of DNP under direct solar irradiation is given in Figure 11. In support of this mechanism, total organic carbon (TOC) and chemical oxygen demand (COD) experiments were performed, as given in Figure S3.

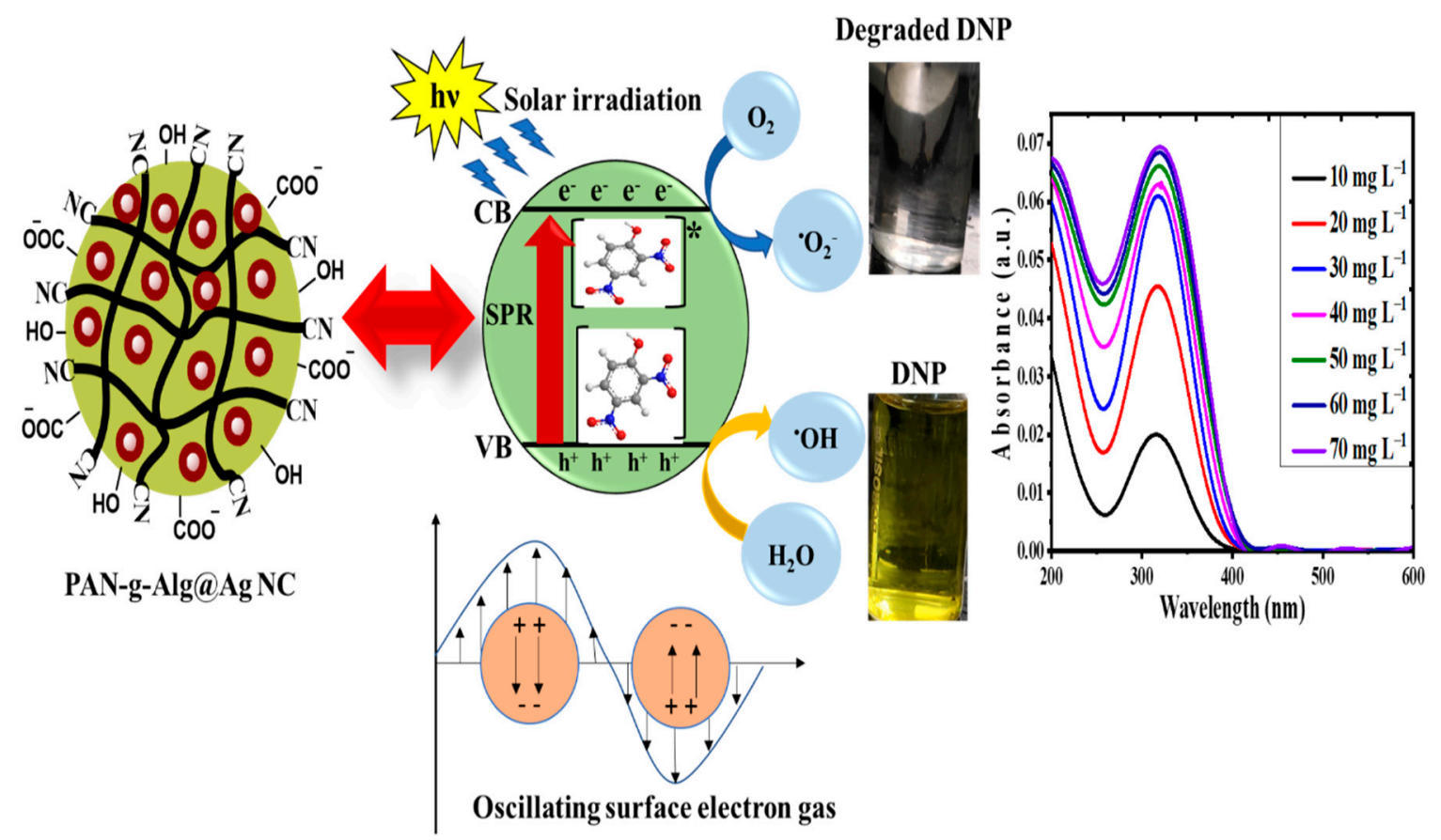

Figure 11. Photodegradation mechanism of DNP by PAN-g-Alg@Ag under direct solar irradiation.

\subsection{Regeneration and Reusability of PAN-g-Alg@Ag NC and Alg@Ag NPs}

One of the important problems associated with advance oxidative technology is the safe disposal of the spent catalyst. This hurdle was later overcome by researchers through the regeneration process, which involves the recovery of the spent catalyst for reuse, thus reducing the cost of the experiment. In the present study, regeneration and reusability experiments were performed for both PAN-g-Alg@Ag NC and Alg@Ag NPs by solvent washing method in which $0.03 \mathrm{~g}$ of catalysts after DNP degradation process was mixed with $20 \mathrm{~mL}$ of $0.1 \mathrm{M} \mathrm{HNO}_{3}$ solution and placed under sonication equipped with magnetic stirrer. The catalysts were collected by filtration and washed by distilled water until the effluent $\mathrm{pH}$ becomes neutral and dried in hot air oven for $2 \mathrm{~h}$ at $60^{\circ} \mathrm{C}$. The recovered catalysts were again utilized for the photodegradation of DNP at the optimized conditions under direct solar irradiation, and the results for photocatalytic efficiency of both PAN-g-Alg@Ag NC and Alg@Ag NPs are given in Figure S4. In the first cycle, the DNP degradation rates for the two catalysts were $97.23 \%$ 
and $88.75 \%$, respectively. Further unitizing the catalysts for second, third, fourth, and fifth cycles using the same procedure resulted in percent DNP degradations of $94.64 \%$ and $85.32 \%, 91.88 \%$ and $81.98 \%$, $89.11 \%$ and $75.39 \%$, and $84.67 \%$ and $62.64 \%$, respectively. In five cycles, the decrement of only $12.56 \%$ in photocatalytic efficiency of PAN-g-Alg@Ag NC as compared to Alg@Ag NPs (26.11\%) suggested that the synthesized PAN-g-Alg@Ag NC is highly efficient and chemically more stable than Alg@Ag NPs for treatment of water contaminated by DNP due to functionalization of polymer blend of PAN.

\subsection{Comparison with Literature}

The advantage of using PAN-g-Alg@Ag NC was explored by comparing the degradation efficiency of the material towards DNP with previously reported studies. The results given in Table 5 suggest that the present study with $99.46 \%$ DNP degradation in just 35 min under visible solar irradiation was highly efficient as compared to the other reported photocatalysts.

Table 5. Comparison of degradation efficiency of PAN-g-Alg@Ag NC with previously reported studies.

\begin{tabular}{|c|c|c|c|c|c|}
\hline Material/Photocatalyst & $\begin{array}{l}\text { Irradiation } \\
\text { Time (min) }\end{array}$ & $\mathrm{pH}$ & Kinetics & $\begin{array}{c}\% \\
\text { Degradation } \\
\text { of DNP }\end{array}$ & Reference \\
\hline $\mathrm{g}-\mathrm{C}_{3} \mathrm{~N}_{4} / \mathrm{AgI} / \mathrm{ZnO} / \mathrm{CQD}$ & $120 \mathrm{~min}$ & 4 & Langmuir-Hinshelwood & $98 \%$ & [12] \\
\hline $\mathrm{Ag}_{2} \mathrm{CO}_{3} / \mathrm{PSGCN}$ & $120 \mathrm{~min}$ & 4 & Pseudo-first order & $98 \%$ & [17] \\
\hline CMIP-coated $\mathrm{TiO}_{2}$ & $240 \mathrm{~min}$ & 5 & Pseudo-first order & $76 \%$ & [43] \\
\hline $\mathrm{ZnFe}_{2} \mathrm{O}_{4}$ & $15 \mathrm{~min}$ & 3 & Pseudo-first order & $82 \%$ & [4] \\
\hline$\left[\mathrm{Ag}_{4}\left(\mathrm{NO}_{3}\right)_{4}(\mathrm{dpppda})\right] \mathrm{n}$ & $300 \mathrm{~min}$ & 4 & Pseudo-zero order & $93 \%$ & {$[50]$} \\
\hline$\zeta-\mathrm{Bi}_{2} \mathrm{O}_{3} / \mathrm{Bi}_{2} \mathrm{MoO}_{6}$ & $100 \mathrm{~min}$ & 7 & Pseudo-first order & $86 \%$ & [51] \\
\hline $\mathrm{ZnFe}_{2} \mathrm{O}_{4}-\mathrm{ZrO}_{2}$ & $60 \mathrm{~min}$ & 4 & Pseudo-first order & $90 \%$ & [8] \\
\hline molecularly imprinted $\mathrm{TiO}_{2}$ & $240 \mathrm{~min}$ & 4 & Pseudo-first order & $74 \%$ & [14] \\
\hline $\mathrm{Ag} / \mathrm{CuO} / \mathrm{TiO}_{2}$ & $80 \mathrm{~min}$ & 7 & Pseudo-first order & $99 \%$ & [13] \\
\hline PAN-g-Alg@Ag & $35 \mathrm{~min}$ & 4.68 & Pseudo-first order & $99.46 \%$ & Present Study \\
\hline
\end{tabular}

\section{Conclusions}

Herein, we report the synthesis of PAN-g-Alg@Ag nanocomposites via the in situ oxidative free-radical polymerization of acrylonitrile using environmentally friendly Alg@Ag nanoparticles. Various analytical techniques, including FTIR and XRD, were used for characterization studies. We note the reduced intensity of the nitrile functional groups at $2246 \mathrm{~cm}^{-1}$ in the FTIR spectrum as an indication of copolymerization between PAN and Alg, with a corresponding peak at $575 \mathrm{~cm}^{-1}$ for the Ag-O coordination bond. The change in the crystal size of the Alg@Ag NPs from 20 to $8 \mathrm{~nm}$ in the PAN-g-Alg@Ag NC, as verified via XRD, is evidence of the modification of the surface of Alg@Ag NPs through polymerization with PAN, which results in well-dispersed, semi-crystalline solids with adequate functional density. RSM-coupled optimization of the reaction parameters indicate that a photocatalytic capacity of $99.46 \%$ with a desirability of 1.00 can be achieved when the irradiation time is $35 \mathrm{~min}$, the $\mathrm{pH}$ of the DNP solution is 4.68 , and the DNP concentration is $70 \mathrm{mg} \mathrm{L}^{-1}$. Additionally, the reaction is governed by pseudo-first-order kinetics, with the rapid generation of the $\mathrm{OH}$ radical at high DNP concentrations due to the masking effect exerted on the adsorption of DNP molecules on the PAN-g-Alg@Ag NC surface. The combined absorption properties of PAN and Alg@Ag NPs on copolymerization on surface contributed more charge density to SPR in a way to degrade more and more molecules of DNP together with preventing the recombination of electron and hole pairs within the photocatalytic process. In five cycles, the decrement of only $12.56 \%$ in photocatalytic efficiency of PAN-g-Alg@Ag NC as compared to Alg@Ag NPs (26.11\%) suggested that the synthesized PAN-g-Alg@Ag NC is highly efficient and chemically more stable than Alg@Ag NPs for treatment of water contaminated by DNP due to functionalization of polymer blend of PAN. The future implications of this research will allow researchers to develop more efficient materials and reaction routes for the photodegradation of carcinogenic compounds. 
Supplementary Materials: The following are available online at http://www.mdpi.com/2073-4360/12/12/3049/s1, Table S1: Range of the variable parameters; Table S2: Design table including the number of experiments with respect to the obtained experimental and predicted data; Figure S1: Elemental Mapping for C, O, N, and Ag elements constituting PAN-g-Alg@Ag NC; Figure S2: (a) UV-Vis plot; and (b) degradation rate of DNP vs. concentration of $\mathrm{NaCl}$ to observe the effect of electrolyte concentration $(\mathrm{NaCl})$ on the photocatalytic degradation of DNP under direct solar irradiation and optimized reaction conditions; Figure S3: Mineralization of DNP during the photodegradation with PAN-g-Alg@Ag NC using direct solar irradiation: (a) total organic carbon (TOC); and (b) chemical oxygen demand (COD); Figure S4: Regeneration and reusability graphs for PAN-g-Alg@Ag NC and Alg@Ag NPs towards DNP degradation.

Author Contributions: Conceptualization, I.H.; Formal analysis, I.H., C.S. and W.A.; Funding acquisition, A.A.; Investigation, M.A.K. and R.A.K.; Methodology, I.H. and C.S.; Project administration, R.A.K. and A.A.; Supervision, I.H., R.A.K. and A.A.; Writing—original draft, I.H., R.A.K. and A.A.; Writing—review \& editing, I.H. and R.A.K. All authors have read and agreed to the published version of the manuscript.

Funding: The authors extend their appreciation to the Deputyship for Research and Innovation, Ministry of Education in Saudi Arabia for funding this research work through project No. IFKSURG-1438-006.

Conflicts of Interest: Authors declare no conflict of interests.

\section{Abbreviations}

$\begin{array}{ll}\text { Alg } & \text { Alginate } \\ \text { PAN } & \text { Poly(acrylonitrile) } \\ \text { Alg@Ag NPs } & \text { Alginate functionalized Ag nanoparticles } \\ \text { DNP } & \text { 2, 4-Dinitrophenol } \\ \text { FTIR } & \text { Fourier-transform Infrared } \\ \text { SEM } & \text { Scanning Electron Microscope } \\ \text { TEM } & \text { Transmission Electron Microscope } \\ \text { XRD } & \text { X-ray Diffraction } \\ \text { EDX } & \text { Energy-dispersive X-ray spectroscopy } \\ \text { DSC } & \text { Differential Scanning Calorimetry } \\ \text { APS } & \text { Ammonium Persulfate } \\ \text { FAS } & \text { Ferrous Ammonium Sulfate }\end{array}$

\section{References}

1. Bilal, M.; Adeel, M.; Rasheed, T.; Zhao, Y.; Iqbal, H.M.N. Emerging Contaminants of High Concern and Their Enzyme-Assisted Biodegradation-A Review. Environ. Int. 2019, 124, 336-353. [CrossRef]

2. Rahmani, H.; Lakzian, A.; Karimi, A.; Halajnia, A. Efficient Removal of 2,4-Dinitrophenol from Synthetic Wastewater and Contaminated Soil Samples Using Free and Immobilized Laccases. J. Environ. Manag. 2020, 256, 109740. [CrossRef]

3. Ahmad, R.; Hasan, I. Efficient Remediation of an Aquatic Environment Contaminated by $\mathrm{Cr}(\mathrm{VI})$ and 2,4-Dinitrophenol by XG-g-Polyaniline@ZnO Nanocomposite. J. Chem. Eng. Data 2017, 62, 1594-1607. [CrossRef]

4. Zaharia, M.; Mihai, M.; Roman, T.; Zbancioc, G.; Pui, A.; Gradinaru, R.V.; Logigan, C.; Drochioiu, G. Unusual Ferrite Induced Photohydrolysis of Dinitrophenols to Nonaromatic and Nontoxic Derivatives. J. Photochem. Photobiol. A Chem. 2020, 394, 112497. [CrossRef]

5. Zhang, L.; Zheng, S.; Kang, D.E.; Shin, J.Y.; Suh, H.; Kim, I. Synthesis of Multi-Amine Functionalized Hydrogel for Preparation of Noble Metal Nanoparticles: Utilization as Highly Active and Recyclable Catalysts in Reduction of Nitroaromatics. RSC Adv. 2013, 3, 4692-4703. [CrossRef]

6. MirzaHedayat, B.; Noorisepehr, M.; Dehghanifard, E.; Esrafili, A.; Norozi, R. Evaluation of Photocatalytic Degradation of 2,4-Dinitrophenol from Synthetic Wastewater Using $\mathrm{Fe}_{3} \mathrm{O}_{4} @ \mathrm{SiO}_{2} @ \mathrm{TiO}_{2} / \mathrm{R}$.GO Magnetic Nanoparticles. J. Mol. Liq. 2018, 264, 571-578.

7. Hinrichs, R.Z.; Buczek, P.; Trivedi, J.J. Solar Absorption by Aerosol-Bound Nitrophenols Compared to Aqueous and Gaseous Nitrophenols. Environ. Sci. Technol. 2016, 50, 5661-5667. [CrossRef] [PubMed]

8. Chen, X.; Liu, Y.; Xia, X.; Wang, L. Popcorn Balls-like $\mathrm{ZnFe}_{2} \mathrm{O}_{4}-\mathrm{ZrO}_{2}$ Microsphere for Photocatalytic Degradation of 2,4-Dinitrophenol. Appl. Surf. Sci. 2017, 407, 470-478. [CrossRef] 
9. Wahid, A.; Asiri, A.M.; Rahman, M.M. One-Step Facile Synthesis of $\mathrm{Nd}_{2} \mathrm{O}_{3} / \mathrm{ZnO}$ Nanostructures for an Efficient Selective 2,4-Dinitrophenol Sensor Probe. Appl. Surf. Sci. 2019, 487, 1253-1261.

10. Marimuthu, S.; Antonisamy, A.J.; Malayandi, S.; Rajendran, K.; Tsai, P.C.; Pugazhendhi, A.; Ponnusamy, V.K. Silver Nanoparticles in Dye Effluent Treatment: A Review on Synthesis, Treatment Methods, Mechanisms, Photocatalytic Degradation, Toxic Effects and Mitigation of Toxicity. J. Photochem. Photobiol. B Biol. 2020, 205, 111823. [CrossRef]

11. Nariya, P.; Das, M.; Shukla, F.; Thakore, S. Synthesis of Magnetic Silver Cyclodextrin Nanocomposite as Catalyst for Reduction of Nitro Aromatics and Organic Dyes. J. Mol. Liq. 2020, 300, 112279. [CrossRef]

12. Hasija, V.; Sudhaik, A.; Raizada, P.; Hosseini-Bandegharaei, A.; Singh, P. Carbon Quantum Dots Supported AgI/ZnO/Phosphorus Doped Graphitic Carbon Nitride as Z-Scheme Photocatalyst for Efficient Photodegradation of 2, 4-Dinitrophenol. J. Environ. Chem. Eng. 2019, 7, 103272. [CrossRef]

13. Zhang, X.; Wang, L.; Liu, C.; Ding, Y.; Zhang, S.; Zeng, Y.; Liu, Y.; Luo, S. A Bamboo-Inspired Hierarchical Nanoarchitecture of $\mathrm{Ag} / \mathrm{CuO} / \mathrm{TiO}_{2}$ Nanotube Array for Highly Photocatalytic Degradation of 2,4-Dinitrophenol. J. Hazard. Mater. 2016, 313, 244-252. [CrossRef] [PubMed]

14. Fiorenza, R.; Di Mauro, A.; Cantarella, M.; Privitera, V.; Impellizzeri, G. Selective Photodegradation of 2,4-D Pesticide from Water by Molecularly Imprinted TiO 2. J. Photochem. Photobiol. A Chem. 2019, 380, 111872. [CrossRef]

15. Singh, P.; Sudhaik, A.; Raizada, P.; Shandilya, P.; Sharma, R.; Hosseini-Bandegharaei, A. Photocatalytic Performance and Quick Recovery of $\mathrm{BiOI} / \mathrm{Fe}_{3} \mathrm{O}_{4}$ @graphene Oxide Ternary Photocatalyst for Photodegradation of 2,4-Dintirophenol under Visible Light. Mater. Today Chem. 2019, 12, 85-95. [CrossRef]

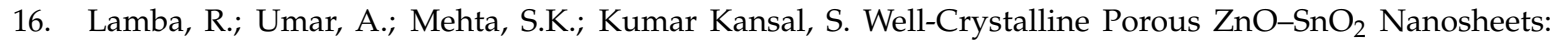
An Effective Visible-Light Driven Photocatalyst and Highly Sensitive Smart Sensor Material. Talanta 2015, 131, 490-498. [CrossRef]

17. Raizada, P.; Sudhaik, A.; Singh, P.; Shandilya, P.; Thakur, P.; Jung, H. Visible Light Assisted Photodegradation of 2,4-Dinitrophenol Using $\mathrm{Ag}_{2} \mathrm{CO}_{3}$ Loaded Phosphorus and Sulphur Co-Doped Graphitic Carbon Nitride Nanosheets in Simulated Wastewater. Arab. J. Chem. 2020, 13, 3196-3209. [CrossRef]

18. Ganapathy Selvam, G.; Sivakumar, K. Phycosynthesis of Silver Nanoparticles and Photocatalytic Degradation of Methyl Orange Dye Using Silver (Ag) Nanoparticles Synthesized from Hypnea Musciformis (Wulfen) J.V. Lamouroux. Appl. Nanosci. 2015, 5, 617-622. [CrossRef]

19. Jana, J.; Ganguly, M.; Pal, T. Enlightening Surface Plasmon Resonance Effect of Metal Nanoparticles for Practical Spectroscopic Application. RSC Adv. 2016, 6, 86174-86211. [CrossRef]

20. Huang, S.; Xiao, Z.; Zhai, S.; Zhai, B.; Zhang, F.; An, Q. Fabrication of Highly-Stable Ag/CA@GTA Hydrogel Beads and Their Catalytic Application. RSC Adv. 2014, 4, 60460-60466. [CrossRef]

21. Paques, J.P.; Van Der Linden, E.; Van Rijn, C.J.M.; Sagis, L.M.C. Preparation Methods of Alginate Nanoparticles. Adv. Colloid Interface Sci. 2014, 209, 163-171. [CrossRef] [PubMed]

22. Zahoor, A.; Sharma, S.; Khuller, G.K. Inhalable Alginate Nanoparticles as Antitubercular Drug Carriers against Experimental Tuberculosis. Int. J. Antimicrob. Agents 2005, 26, 298-303. [CrossRef] [PubMed]

23. Khalil, A.; Nasser, W.S.; Osman, T.A.; Toprak, M.S.; Muhammed, M.; Uheida, A. Surface Modified of Polyacrylonitrile Nanofibers by $\mathrm{TiO}_{2} / \mathrm{MWCNT}$ for Photodegradation of Organic Dyes and Pharmaceutical Drugs under Visible Light Irradiation. Environ. Res. 2019, 179, 108788. [CrossRef] [PubMed]

24. Ahmad, R.; Hasan, I. Optimization of the Adsorption of Pb (II) from Aqueous Solution onto PAB Nanocomposite Using Response Surface Methodology. Environ. Nanotechnol. Monit. Manag. 2016, 6, 116-129. [CrossRef]

25. Yang, H.Y.; Liu, J.; Wang, Y.X.; He, C.S.; Zhang, L.S.; Mu, Y.; Li, W.H. Bioelectrochemical Decolorization of a Reactive Diazo Dye: Kinetics, Optimization with a Response Surface Methodology, and Proposed Degradation Pathway. Bioelectrochemistry 2019, 128, 9-16. [CrossRef] [PubMed]

26. Samarbaf, S.; Tahmasebi Birgani, Y.; Yazdani, M.; Babaei, A.A. A Comparative Removal of Two Dyes from Aqueous Solution Using Modified Oak Waste Residues: Process Optimization Using Response Surface Methodology. J. Ind. Eng. Chem. 2019, 73, 67-77. [CrossRef]

27. Hasan, I.; Bhatia, D.; Walia, S.; Singh, P. Removal of Malachite Green by Polyacrylamide-g-Chitosan $\gamma-\mathrm{Fe}_{2} \mathrm{O}_{3}$ Nanocomposite-an Application of Central Composite Design. Groundw. Sustain. Dev. 2020, 11, 100378. [CrossRef] 
28. Hasan, I.; Khan, R.A.; Alharbi, W.; Alharbi, K.H.; Abu Khanjer, M.; Alslame, A. Synthesis, Characterization and Photo-Catalytic Activity of Guar-Gum-:G-Aliginate@silver Bionanocomposite Material. RSC Adv. 2020, 10, 7898-7911. [CrossRef]

29. Shah, A.P.; Sharma, A.S.; Sharma, V.S.; Shimpi, N.G. Polyacrylonitrile Nanofibers Incorporating Silver-Decorated Graphitic Carbon Nitride for the Visible-Light-Activated Selective Oxidation of Styrene, Benzylic Methylene Groups, and Benzene. ACS Appl. Nano Mater. 2020, 3, 1922-1933. [CrossRef]

30. Voo, W.P.; Lee, B.B.; Idris, A.; Islam, A.; Tey, B.T.; Chan, E.S. Production of Ultra-High Concentration Calcium Alginate Beads with Prolonged Dissolution Profile. RSC Adv. 2015, 5, 36687-36695. [CrossRef]

31. Bhagyaraj, S.; Krupa, I. Alginate-Mediated Synthesis of Hetero-Shaped Silver Nanoparticles and Their Hydrogen Peroxide Sensing Ability. Molecules 2020, 25, 435. [CrossRef] [PubMed]

32. Zhang, J.; Lu, Z.; Wu, M.; Wu, Q.; Yang, J. Large-Scale Synthesis and Characterization of Magnetic Poly (Acrylic Acid) Nanogels via Miniemulsion Polymerization. RSC Adv. 2015, 5, 58889-58894. [CrossRef]

33. Hebeish, A.A.; Ramadan, M.A.; Montaser, A.S.; Farag, A.M. Preparation, Characterization and Antibacterial Activity of Chitosan-g-Poly Acrylonitrile/Silver Nanocomposite. Int. J. Biol. Macromol. 2014, 68, 178-184. [CrossRef] [PubMed]

34. Rehan, M.; Nada, A.A.; Khattab, T.A.; Abdelwahed, N.A.M.; El-Kheir, A.A.A. Development of Multifunctional Polyacrylonitrile/Silver Nanocomposite Films: Antimicrobial Activity, Catalytic Activity, Electrical Conductivity, UV Protection and SERS-Active Sensor. J. Mater. Res. Technol. 2020, 9, 9380-9394. [CrossRef]

35. Venkatesan, J.; Lee, J.Y.; Kang, D.S.; Anil, S.; Kim, S.K.; Shim, M.S.; Kim, D.G. Antimicrobial and Anticancer Activities of Porous Chitosan-Alginate Biosynthesized Silver Nanoparticles. Int. J. Biol. Macromol. 2017, 98, 515-525. [CrossRef]

36. Scherrer, P. Estimation of the Size and Internal Structure of Colloidal Particles by Means of Rontgen Rays. Nachrichten von der Gesellschaft der Wissenschaften zu Göttingen 1918, 26, 98-100.

37. Mehmood, A.; Murtaza, G.; Bhatti, T.M.; Kausar, R. Phyto-Mediated Synthesis of Silver Nanoparticles from Melia Azedarach, L. Leaf Extract: Characterization and Antibacterial Activity. Arab. J. Chem. 2017, 10, S3048-S3053. [CrossRef]

38. Soltani, I.; Hraiech, S.; Horchani-Naifer, K.; Elhouichet, H.; Gelloz, B.; Férid, M. Growth of Silver Nanoparticles Stimulate Spectroscopic Properties of Er3+ Doped Phosphate Glasses: Heat Treatment Effect. J. Alloy. Compd. 2016, 686, 556-563. [CrossRef]

39. Ghanavati Nasab, S.; Semnani, A.; Karimi, M.; Javaheran Yazd, M.; Cheshmekhezr, S. Synthesis of Ion-Imprinted Polymer-Decorated SBA-15 as a Selective and Efficient System for the Removal and Extraction of $\mathrm{Cu}$ (II) with Focus on Optimization by Response Surface Methodology. Analyst 2019, 144, 4596-4612. [CrossRef]

40. Anfar, Z.; El Haouti, R.; Lhanafi, S.; Benafqir, M.; Azougarh, Y.; El Alem, N. Treated Digested Residue during Anaerobic Co-Digestion of Agri-Food Organic Waste: Methylene Blue Adsorption, Mechanism and CCD-RSM Design. J. Environ. Chem. Eng. 2017, 5, 5857-5867. [CrossRef]

41. Wang, Z.; Ge, H.; Wang, X.; Ye, C.; Fan, S. Mono and Co-Immobilization of Imidazolium Ionic Liquids on Silica: Effects of the Substituted Groups on the Adsorption Behavior of 2,4-Dinitrophenol. RSC Adv. 2019, 9 , 32425-32434. [CrossRef]

42. Zhou, X.; Lai, C.; Huang, D.; Zeng, G.; Chen, L.; Qin, L.; Xu, P.; Cheng, M.; Huang, C.; Zhang, C.; et al. Preparation of Water-Compatible Molecularly Imprinted Thiol-Functionalized Activated Titanium Dioxide: Selective Adsorption and Efficient Photodegradation of 2, 4-Dinitrophenol in Aqueous Solution. J. Hazard. Mater. 2018, 346, 113-123. [PubMed]

43. Shandilya, P.; Mittal, D.; Sudhaik, A.; Soni, M.; Raizada, P.; Saini, A.K.; Singh, P. GdVO 4 Modified Fluorine Doped Graphene Nanosheets as Dispersed Photocatalyst for Mitigation of Phenolic Compounds in Aqueous Environment and Bacterial Disinfection. Sep. Purif. Technol. 2019, 210, 804-816. [CrossRef]

44. Park, S.J.; Das, G.S.; Schütt, F.; Adelung, R.; Mishra, Y.K.; Tripathi, K.M.; Kim, T.Y. Visible-Light Photocatalysis by Carbon-Nano-Onion-Functionalized ZnO Tetrapods: Degradation of 2,4-Dinitrophenol and a Plant-Model-Based Ecological Assessment. NPG Asia Mater. 2019, 11, 1-13. [CrossRef]

45. García Einschlag, F.S.; Lopez, J.; Carlos, L.; Capparelli, A.L.; Braun, A.M.; Oliveros, E. Evaluation of the Efficiency of Photodegradation of Nitroaromatics Applying the UV/H2O2 Technique. Environ. Sci. Technol. 2002, 36, 3936-3944. [CrossRef] 
46. Mavaei, M.; Chahardoli, A.; Shokoohinia, Y.; Khoshroo, A.; Fattahi, A. One-Step Synthesized Silver Nanoparticles Using Isoimperatorin: Evaluation of Photocatalytic, and Electrochemical Activities. Sci. Rep. 2020. [CrossRef]

47. Mangalam, J.; Kumar, M.; Sharma, M.; Joshi, M. High Adsorptivity and Visible Light Assisted Photocatalytic Activity of Silver/Reduced Graphene Oxide (Ag/RGO) Nanocomposite for Wastewater Treatment. Nano Struct. Nano Objects 2019, 17, 58-66. [CrossRef]

48. Roushani, M.; Mavaei, M.; Rajabi, H.R. Graphene Quantum Dots as Novel and Green Nano-Materials for the Visible-Light-Driven Photocatalytic Degradation of Cationic Dye. J. Mol. Catal. A Chem. 2015, 409, 102-109. [CrossRef]

49. Silva, I.M.P.; Byzynski, G.; Ribeiro, C.; Longo, E. Different Dye Degradation Mechanisms for ZnO and ZnO Doped with N (ZnO:N). J. Mol. Catal. A Chem. 2016, 417, 89-100. [CrossRef]

50. Wu, X.Y.; Qi, H.X.; Ning, J.J.; Wang, J.F.; Ren, Z.G.; Lang, J.P. One silver(I)/tetraphosphine coordination polymer showing good catalytic performance in the photodegradation of nitroaromatics in aqueous solution. Appl. Catal. B Environ. 2015, 168, 98-104.

51. Ma, J.; Zhang, L.Z.; Wang, Y.H.; Lei, S.L.; Luo, X.B.; Chen, S.H.; Zeng, G.S.; Zou, J.P.; Luo, S.L.; Au, C.T. Mechanism of 2,4-Dinitrophenol Photocatalytic Degradation by $\zeta$-Bi2O3/Bi2MoO6 Composites under Solar and Visible Light Irradiation. Chem. Eng. J. 2014, 251, 371-380. [CrossRef]

Publisher's Note: MDPI stays neutral with regard to jurisdictional claims in published maps and institutional affiliations. 